\title{
Ophthalmologische Miscellen
}

\author{
ron \\ Dr. Wilhelm Rau, \\ Professor der Medicin in Bern.
}

I. Bemerkungen über einige Krankheiten der Thränenorgane.

1) Cauterisation des verengerten Nasenkanals durch in Hollensteinsolution getränkte Darmsaiten.

Es sind über zehn Jahre verflossen, scitdem ich auf die Idee kam, verengerte oder verschlossene Kanäle mit Darmsaiten zu cauterisiren, welche in einer concentrirten IÏ̈llensteinsolution getränkt, getrocknet eingeführt, die Aetzwirkung mit einer gleichzcitigen Dilatation verbinden sollten. Die ersten Versuche mit solchen Saiten stellte ich bei Verschliessung der Eustachischen Trompete an, und publicirte dieselben in einem in der Versammlung der schweizerischen naturforschenden Gesellschaft zu Chur im Jahre 1844 gehaltenen Vortrage über den Catheterismus der Eustachischen Trompete, welcher im ersten Hefte der schweizerischen Zeitschrift für Medicin, Chirurgie und Geburtshülfe, 1845, S. 36-51 abgedruckt ist. Später dehnte ich die Versuche auch auf andere verengerte Kanäle, namentlich die Harmüöre und den Nasenkanal aus, und erörterte das Verfahren in einem Vortrage über eine neue Cauterisationsmethode in der Versammlung der deutschen naturforschenden Gesellschaft in Archiv fïr Oplulialm. I. 2. 
Nürnberg im Jahre 1845, den der amtliche Bericht über die 23. Versammlung deutscher Naturforscher und $\Lambda$ erzte in Nürnberg im September 1845, Nürnberg 184\%. 4. S. 209-210, in gedrängtem Auszuge enthält.

Diese Mittheilungen schienen kaum beachtet worden zu sein, bis $D$ ubois in den Annales d'Oculistique, Mars 1853, mein Verfahren als eine neue Methode zur Behandlung von Verengerungen des Nasenkanals anpries, welche als cine ausländische Frfindung die allgemeine Aufmerksamkeit erregte, und in verschiedenen Zeitschriften, unter anderen in Schmidt's Jahrbüchern (1854. Nr. 1. S.90), eine sehr anerkemnende Beurtheilung gefunden hat. Da über die Priorität kein Zwweifel obwalten kann, so mag es dahin gestellt bleiben, ob I) ubois unabhängig von mir auf dieselbe Idee gekommen sei. Jedenfalls ist es interessant, und spricht für den Werth des Verfahrens, dass er genau dieselben Resultate erhiclt, wie ich sie in zahlreichen Fallen erzielt habe. Aus diesem Grunde halte ich es nicht für überflüssig, in Folgendem mein Verfahren etwas näher zu erörtern.

I)ie in Stücke von entsprechender Länge zerschnittenen Darmsaiten werden, zunächst an dem einen Ende, möglichst glatt abgerundet, was am bequemsten mit einer ganz feinen englischen Feile geschieht, und dann mit Aetzkalilauge abgewaschen, da sie in der Regel beölt sind. Hierauf taucht man sie so weit in eine starke Höllensteinaufösung (etwa 1 Theil auf 10 Theile destillirtes Wasser), als sic in die verengerte Stelle eindringen sollen, entfernt sie je nach der Dicke nach 4 bis 8 Stunden, um sie, am besten frei angehängt, an cinem dunkeln Orte zu trocknen. Fine mit Aetzkalilauge vom Fettgehalte befreite Saite ist in der erwähnten Zeit so vollständig getränkt, dass sic nichts mehr aufnehmen kann. Längeres Maceriren hat sogar den Nachtheil, dass sich die Saite gern aufdreht, krümmt und eine unebene 
Oberfläche erhält. Nach dem Trocknen ist dieselbe nicht blos an der Oberfläche mit einer krystallinischen Höllensteinschicht überzogen, sondern in ihrem ganzen Gewebe davon durchdrungen. Sollte das untere Ende etwas kolbig angeschwollen sein, so muss dasselbe wiederholt durch einige Feilenstriche abgerundet werden. Vor dem Lichte geschützt, am bequemsten in einem geschwärzten Glasröhrchen, lassen sich die präparirten Saiten Monate lang aufbewahren, ohne an Wirksamkeit zu verlieren. Dic mit Höllenstcin getränkte Stelle hat eine weisslichgraue, bisweilen etwas ins Röthliche schimmernde Farbe. Taucht man Stücke von verschiedenen Saiten zugleich ein, so nehmen dieselben oft eine ganz abweichende Färbung an. Die Anfangs gehegte Besorgniss, es möge der Iöllenstein zerstörend auf die Saite oder diese zersetzend auf jenen einwirken, hat sich glücklicher Weise als unbegründet erwiesen. Die Saite behält ihre Festigkeit, nimmt aber allmählig eine röthlich-braune, selbst schwärzliche Farbe an, ohne jedoch eine merklich schwächere Wirkung zu äussern. Vor länger als einem Jahre präparirte Saiten in destillirtes Wasser gelegt, theilten diesem lraum eine Färbung mit, und zugetröpfelte Kochsalzlösung gab einen reichlichen Niederschlag von ganz weissem Chlorsilber. Reducirtes Silber konnte ich niemals entdecken.

Sollen die Saiten zum Gebrauche bei Verengerungen des Nasenkanals, bei der sogenannten Thränenfistel, dienen, so wird das obere Ende mit einem Mammer platt geschlagen und hakenförmig umgebogen, so dass es aus der Fistclöffnung hervorragend, sich platt anlegt, und mit einem Stückchen englischen Pflasters, oder mit Collodium getränktem Läppchens von porösem Stoffe kaum sichtbar befestigt werden kann. Nach reinigenden Injectionen wird die Saite unbeült so tief eingeführt, bis sie von der Verengerung festgehalten wird. Anfangs be- 
diente ich mich zur Einführung eines silbernen, vergoldeten Röhrchens, welches ich aber ]ängst schon als ganz überflüssig, selbst hinderlich, nicht mehr anwende. Von der Aetzwirkung empfindet der Kranke während der Einführung der Saite nicht das Mindeste, wohl aber entsteht später ein mehr oder weniger lebhaftes Brennen, welches einige Stunden anhält, übrigens in keinem Falle so stark wurde, dass ich mich zur Kntfernung der Saite vor Ablauf von 24 Stunden veranlasst gefunden hätte. Ist die Reizung wie gewöhnlich nicht sehr bedentend, so wird täglich eine neue präparirte Saite eingeführt, nachdem der Kanal durch Injectionen von lauem Wasser oder einer Kupfervitriolauflösung gereinigt ist. Schon nach einmaliger $\Lambda$ pplication zeigt sich, dass eine Saite von demselben Durchmesser viel leichter und merklich tiefer eindringt, indem die Wirkung der Cauterisation durch das Aufquellen der Saite fixirt wird. Man kann deshalb sehr rasch zu dickeren Saiten übergehen, bis der Kanal die gehörige Weite erlangt hat. Sollte sich eine stärkere Reizung nach wiederholter Cauterisation cinstellen, so legt man eine einfache Saite bis zu deren Beseitigung ein. Ist der Kanal gehörig erweitert, dringen Injectionen mit Leichtigkeit in vollem Strahle durch die Nase, hat das Secretum die eiterige Beschaffenheit verloren, so lässt man am besten noch cinige Zeit cinen Bleidrath tragen, bevor man die Fistelöffnung zum Schliessen bringt.

Wer sich vielfach mit der Behandlung von Thränensackfisteln nach den bisher üblichen Methoden beschäftigt hat, wird die grossen Vorzüge des geschilderten Verfahrens zu würdigen wissen, wclche hauptsächlich in einem sehr beträchtlichen Zeitgewinn bestehen. Verengerungen des Nasenkanals, welche nicht mit $\Lambda$ bnormitäten der knöchernen l'artie in Verbindung stehen, lassen sich in wenigen Wochen gründlich heben, wozu nach 
anderen Methoden mehr als eben so viele Monate erforderlich sind. In einem erst kürzlich in der Poliklinik behandelten Falle, wo eine feine Anel'sche Sonde Anfangs mit grosser Mühe bis in die Nase geführt werden konnte, gelang die Heilung so rasch, dass Patient nach vierzehn Tagen entlassen werden konnte. Dies ist allerdings ein Ausnahmefall, und es dürfte sogar nicht rathsam sein, in der Regel so rasch zu verfahren. Dass mir Recidive vorgekommen sind, kann ich nicht leugnen. Sie betrafen jedesmal nur Fälle, in denen die Kur allzu sehr beschleunigt wurde, waren aber höchst selten, und wurden durch Wiederholung des gleichen Verfahrens beseitigt. Dauernde Heilung habe ich aber in allen übrigen Fällen erziclt, wo eine solche überhaupt müglich war. Bei einer vor zehn Jahren von mir behandelten Frau, welche sich vor wenigen Tagen wegen eines Glaucoms in der Poliklinik einstellte, zeigte sich keine Spur des früheren Cebels mehr.

Um bei geringeren Graden von Verengerung des Nasenkanals, die wahrscheinlich von einfacher Auflockerung der Schleimhaut abhängen, milder zu cauterisiren, versuchte ich mehrfach die Anwendung von Darmsaiten, die ich in einer Solution von mit Salpeter zusammengeschmolzenem Möllenstein getränkt hatte, ohne irgend einen Vortheil davon wahrzunehmen. Den gleichen Zweck erreicht man, wenn man die Saiten nur kurze Zeit in die reine IIöllensteinlösung eintaucht, so dass sie nicht ganz davon durchdrungen werden. Dagegen bediene ich mich in solchen Fällen bisweilen mit gutem Erfolge der in eine concentrirte Kupfervitriollösung getauchten Darmsaiten. Da übrigens der Kupfervitriol weniger leicht in das, Gewebc der Saiten eindringt als der IIöllenstein, so ist es nöthig, dieselben zuvor einige Minuten in lauem Wasser zu crweichen, nachdem sie mit Actzkalilauge abgewaschen worden sind. Dass auch andere Metallsalze 
in ähnlicher Weise benutzt werden künnen, unterliegt keinem Zweifel, wiewohl ich mich bis jetzt auf die Versuche mit den erwähnten beschränkt habe.

2) Behandlung der Blennorihöe des Thränensackes mittelst Injectionen durch den Nasenkanal.

Diese nach zufälligen Verschiedenheiten mit den heterogensten Nainen belegte, bald als Entzündung, bald als Erschlaffung des Thränensackes, bald als Verdichtung dessen Inhalts aufgefasste Krankheit ist wesentlich eine mit Anhäufung des zähen Secretums verbundene Verengerung der unteren Partie des Nasenkanals. Da keine Verschliessung besteht, so kann der flüssige Inhalt noch nach unten abfliessen, weshalb die Nasenhälfte der leidenden Seite nio ganz trocken ist. Von der Nase ausgehend, ist die Blennorrhüe des Thränensackes in der Regel Folge eines langwierigen Schnupfens, bisweilen Reflex exanthematischer Eruptionen, namentlich bei dyscratischen Individuen. Aus diesen Andeutungen erklärt sich zur Genüge, weshalb die gewöhnlich empfohlenen Mittel nur selten ihrem Zwecke entsprechen können. Die alte Methode, durch Linspritzungen von der Nase aus auf die krankhaft veränderte Schleimhaut direct einzuwirken ist jedenfalls rationeller, als die aus bekannten Gründen misslicheren Injectionen durch die Thränenpünktchen. Sie wurde übrigens wegen der Sehwierigkeit der Ausführung mit den früher dazu benutzten unvollkommenen Instrumenten längst wieder verlassen, fand in den Handbüchern nur-noch eine historische Erwahnung, bis sie in neuester Zeit, der Vergessenheit entrissen, eine solche Vervollkommnung erlangt hat, dass sie in der Behandlung der in Rede stehenden Krankheit eine wichtige Rolle zu spielen bestimmt scheint. Um über die Widersprüche hinsichtlich des Nutzens dieser Methode ein sicheres Urtheil zu gewinnen, entschloss ich mich 
zu einel praktischen Prüfung. Durch Versuche an durchsägten Küpten machte ich mich zunächst mit den anatomischen Verhältnissen der betreffenden 'Theile, so wie mit dem Mechanismus der Einführung der Instrumente vertraut, bevor ich an Lebenden experimentirte. Ich bediente mich der silbernen Gensoul'schen Catheter nach der neuesten Verbesserung, die ich nach einem von Herrn Iofrath Ructe in Leipzig vor einigen Jahren erhaltenen Modell anfertigen liess. Die Schwierigkeiten, welche Manche von Versuchen abschreckten, waren bald überwunden, und es gelang mir bei normaler Nasenbildung stets leicht, den Catheter einzufübren, so dass die injicirte Flüssigkeit durch die Thränenpünktchen zum Vorschein kam. War auch die Einführung des Instruments nie so schmerzhaft, dass mir Kranke deshalb weggeblieben wären, wie dies Anderen begegnet ist, so verursachte sie doch stets eine viele Stunden anhaltende sehr unangenehme Hmpfindung. Da ich mich längst schon zum Catheterismus der Eustachischen I'Trompete selbstverfertigter Instrumente, aus einem mit GuttaPercha überschmolzenen Seidengewebe, mit grösserer Bequernlichkeit für den Kranken bediente, so lag die Idee nahe, solche auch für den Nasenkanal zu versuchen. Es gelang mir in der That auch, Catheter aus Gutta-Percha genau nach den Dimensionen der Gens oul'schen herzustellen, welche sich bei der Anwendung bewährten. Sie sind zwar wegen der Ilasticität etwas schwicriger einzuführen, als die unnachgiebigen silbe.nen, erregen aber eine weit weniger unangenehme Lmpfindung. Zurn Krlernen des Catheterismus des Nasenkanals lasse ich deshalb meine Zuhörer stets mit silbernen Instrumenten beginnen, bis sie mit diesen cine gewisse Fertigkeit erlangt haben. Ueber die Verfertigung der Catheter auf die Inauguraldissertation von Clemens*)

*) Ch. Fr. Clemens, der Catarrh des Thränenkanais und des 
verweisend, möge zunächst die Darstellung des Catheterismus des Nasenkanals hier folgen.

Das mit dem Schnabel nach abwärts und mit der Seitenkrümmung nach auswärts gerichtete, wie eine Schreibfeder gehaltene Instrument (man bedarf für jede Nasenhälfte einen besonderen Catheter mit entsprechender Seitenkrümmung) wird, unter einer rotirenden Bewegung, unter die untere Muschel geführ, mit der Spitze Anfangs nach abwärts, dann nach aufwärts gerichtet, bis es längs des Muschelrandes fortgleitend, beim behutsamen Vorschieben oben einen Widerstand findet. An dieser Stelle angelangt, wird es in der Regel in einer kleinen Knochengrube festgehalten, welche leicht mit der Mündung verwechselt werden kaun. Um in die etwas weiter nach vorn gelegene Mündung zu gelangen, zicht man den nach oben leicht angedrủckten Schnabel so weit zurück, bis er in der Vertiefung festsitzt. Hierauf drückt man denselben so weit wie möglich nach oben, indem man die Spitze des Zeigefingers der anderen IIand dicht an der Nasenöffnung unter den Catheter schiebt. Vor dem Einführen des Schnabels in die Mündung des Nasenkanals lässt man den Kranken tief inspiriren, um die Thrånenklappe zu öffnen, welche für gewöhnlich kein Hinderniss abgiebt, in manchen Fällen jedoch, wegen abweichender Bildung, den Catheterismus ohne Zerreissung derselben unmöglich machen kann. Herr Prof. Theile zeigte mir ein Präparat, an welchem statt einer eigentlichen Klappe eine röhrenförmige, sich mehrere Linien über die Muschel erstreckende Verlängerung der Schleimhaut vorhanden war. Aehnliche Abnormitäten sind auch bereits von Anderen beobachtet worden.

mittleren Ohrs und seine Heilung, vorzüglich durch örtliche Mittel, mit besonderer Berücksichtjgung der zu diesem Zwecke von $H$. Dr. W. Rau, Professor der Medicin in Bern, erfundenen Catheter. Bern 1852. S. $30-32$, 
Béraud fand z. B. in zwei Fällen den Kanal dureh eine abnorme Insertion der Klappe in zwei Hälften getheilt, ausserdem die Sehne des Musc. obliquus genau an der Stelle inserirt, wo sich die untere Klappe befindet.

Die nach dieser Beschreibung höchst umständlich scheinende Operation ist zwar ungleich schwieriger, als der Catheterismus der Eustachischen Trompete, lässt sich aber, bei einiger Lebung, mit grosser Sicherheit ziemlich rasch ausführen. Mehrere Studirende haben unter meiner Anleitung in der Poliklinik sehr bald eine solche Fertigkeit erlangt, dass ich ihnen Paticnten anvertrauen konnte. Immerhin erfordert die Operation eine grosse Dexterität, wenn sie ohne Beschwerde für den Kranken verrichtet werden soll.

Um Injectionen durch den Catheter vorzunehmen, verbindet man dessen Hülse nach der Einführung mit eincr luftdicht schliessenden Spritze. Am einfachsten geht dies, wenn man ein Stückchen eines elastischen Catheters in die Hülse eingefügt lässt, in welches das Röhrchen der Spritze leicht eingesetzt werden kann. Statt der Spritze kann man sich sehr gut eines kleinen Kautschuckballons mit conischem Rohre bedienen, wie man sie zur Luftdouche des mittleren Ohres verwendet. Fine gut gearbeitete kleine Glasspritze genũgt aber vollkommen, um die Flüssigkeiten in den Thränenkanal zu treiben, so dass sie nicht sclten in feinem Strahle aus den Thränenpünktchen hervorspritzen. Immer lasse man den Thränensack vor der Application des Catheters sorgfältig durch einen Druck entleeren, worin die Kranken selbst in der Regel eine grosse Fertigkeit erlangen. Nach der Injection arzneilicher Flüssigkeiten muss dagegen das Ausdrücken unterbleiben. Ich habe mich verschiedener, bei Blennorrhöen überhaupt üblicher Mittel zu Injectionen bedient, ziemlich starke Lösungen von 
Zink- und Kupfervitriol, Lapis divinus, Sublimat, Höllenstein, selbst Kochsalz angewendet, das letztere jedoch nie vor wiederholter Cauterisation, um die Bildung von Chlorsilber zu verhüten, - in einem Falle Jod und Jodkali, ohne einem dieser Mittel einen bestimmten Vorzug einräumen zu können. Die Reinigung des Kanals von dem angesammelten Secretum, so wie die durch den Catheter bewirkte mechanische Erweiterung desselben hat unstreitig einen nicht unwesentlichen Antheil an dem Erfolge. Deshalb ist es aber auch von grösster Wichtigkeit, den Catheter möglichst tief einzuschieben. Geschieht dies, so dringen die Injectionen desto leichter ein, und man hat sicher nicht nüthig, an dem Schnabel des Instruments eine seitliche Oeffnung anzubringen, wie Chossaignac empfichlt: Bei wo möglich täglich wiederholter Injection verliert der Schleim im günstigen Falle ziemlich bald seine zähe Beschaffenheit und gelbliche Farbe, er wird flockig, allmählig wasserbell, vermindert sich, während die häufig bestehende Reizung der äusseren Bedeckungen des Thränensackes schwindet, und dieser seinen Tonus wieder erhält. Von sieben auf diese Weise behandelten Kranken wurden zwei vollständig geheilt, unter diesen eine wegen ihrer Ausdauer erwähnenswerthe Frau rom Lande, welche viele Wochen lang den Weg von zwei Stunden zurücklegte, um sich regelmässig in der Poliklinik einzufinden. Bei drei anderen erfolgte bedeutende Besserung, welche jedoch bei einem derselben, einem jungen Menschen vom Lande, bei dem sich, durch vorausgegangene Ozaena, ein Knochenstückchen aus der Nase abgestossen hatte, nur von kurzer Dauer war. Das Knochenstückchen war so zerfressen, dass selbst ein Anatom, Herr Professor Theile, welcher damals die Poliklinik besuchte, dasselbe nicht $z u$ bestimmen vermochte. Bei den beiden übrigen Patienten zeigte sich gar kein Erfolg nach 
mehrwöchentlicher Behandlung, worauf dieselben wegblieben.

Sind auch diese Resultatc nicht ganz befriedigend, so liefern sie doch wenigstens den unumstösslichen Beweis, dass die den gewöhnlichen Mittcln fast immer widerstehende chronische Blennorrhöe des Thränenkanals durch direkte Finwirkung auf die erkrankte Schleimhautpartie mit Erfolg bekämpft werden kann. Dass dies nicht immer möglich sein wird, liegt in der Natur der Sache. Für solche Fälle bleibt aber immer noch die künstliche Eröffnung des Thränensackes und das Einlegen mit Höllensteinaufösung präparirter Darmsaiten übrig.

3) Insufficienz der Thränenklappe.

Dieses unstreitig äuserst seltene Uebel, welches ich weder in den Handbüchern über Augenheilkunde, noch in den monographischen Bearbeitungen der Krankheiten der Thränenorgane erwähnt fand, ist mir zweimal, und zwar unter verschiedener Form, vorgekommen. Vor längerer Zeit machte mich eine in Bern wohnende Frau von 45 Jahren auf eine sonderbare Anschwellung am Nasenwinkel des linken Auges aufmerksam, welche, seit frühester Kindheit bestehend, durch einen Fall auf die Nase aus beträchtlicher Höhe entstanden sein sollte. An der erwähnten Stelle zeigto sich nämlich eine ziemlich scharf begrenzte Geschwulst von der Grösse einer Haselnuss mit unveränderter Hautfarbe, genau in der Art, wic sie bei Blennorrbüe des Thränensackes vorkommt. Als ich die Fingerspitze zur Untersuchung aufsetzte, war ich nicht wenig überrascht, die Geschwulst, fast ohne Widerstand, augenblicklich verschwinden zu sehen. Nicht minder überraschend war aber die augenblickliche Wiederkehr derselben nach einer starken Exspiration durch dic Nase. Bei ruhiger Respiration füllt sich die durch einen leichten Druck entleerte Geschwulst nach einigen 
Sekunden, indem sich dic etwas faltige Haut zunächst glättet, sodann blasenartig erhebt, während sie durch eine starke Exspiration ohne Verschliessung der Nase fast augenblicklich den hüchsten Grad von Spannung zeigt. Offenbar ist dieselbe nichts anderes, als eine durch Lufteintritt beim Ausathmen bedingte Aufblähung, ein Emphysem des Thrïnensackes, nur erklärlich durch aufgehobene Funktion oder vielleicht Zerstörung der Thränenklappe. In welchem Causalzusammenhang die frühere Nasenverletzung damit steht, ist schwer zu bestimmen. Spuren einer vorhanden gewesenen Fractur der Nasenknochen sind nicht zu ermitteln. Eben so wenig zeigt sich abnorme Secretion des Thränenkanals, und die Thränenleitung ist ungestört. Da die Luft nach unten gar keinen Widerstand zu finden scheint, so konnte ich auch bei raschem Zusammendrücken der Geschwulst keinen Austritt derselben aus den Thränenpünktchen wahrnehmen.

Der zweite Fall betrifft einen zwölfjährigen Knaben, welchen ein Arzt vom Lande, als an beginnender Thränenfistel leidend, an die Augenklinik wiess. Bei diesem zeigte sich die sonderbare Erscheinung, dass beim Schneuzen ein feiner Strahl von Flüssigkeit aus den Thränenpünktchen, stärker aus dem unteren, spritzte. War diese ziemlich entleert, so hörte man bei Wiederholung des Experiments, indem man den Knaben bei zugehaltener Nase stark schnauben liess, die Luft unter zischendem Geräusche ausströmen, wobei einzelne Tröpfchen von Thränen zum Vorschein kamen. Eine Anschwellung des Thränensackes fehlte hier. Ueber die Lntstehung des erst seit Kurzem wahrgenommenen Uebels fehlte jeder Aufschluss. Da der Knabe zugleich an einer leichten Bindehautentzündung litt, und die aus den Thränenpünktchen hervorspritzende Flüssigkeit etwas schleimhaltig zu sein schien, so wurde demselben ein Tropfwasser aus 
Kupfervitriollösung mit Opiumtinctur verordnet. Nach einigen Wochen fand sich derselbe angeblich etwas gebessert wieder ein, was aber nur hinsichtlich der Bindehautentzündung der Fall war. Dic übrigen Erscheinumgen waren noch genau dieselben, wic bei der ersten Untersuchung. Drei Monate später hatte das Hervorspritzen der Thränen beim Schnauben aufgehört, wiewohl das zischende Geräusch noch deutlich wahrgenommen werden konnte. Dass die auch in diesem Falle in Unwirksamkeit versetzte Thränenklappe selbst bei Gesunden nicht immer luftdicht schliest, geht aus dem Umstande hervor, dass Manche bei geschlossenem Munde und zugehaltener Nase, durch gewaltsame Exspiration, Luft aus den Thränenpünktchen hervortreiben können. Die Genesis des nach Quctschungen am imneren Augenwinkel mit Zerrcissung eines Thränenröhrchens entstehenden Emphysems der Augenlieder beruht auf demselben Verhulltnisse, indem die, beim gewaltsamen Niesen oder Schneuzen, in den Thränenkanal gelangte Luft in das Zellgewebe getrieben wird.

4) Anchyloblepharon partiale des inneren Augenwinkels als seltene Ursache des Thräncnträufelns.

Bei ciner ïlteren Frau, welche mich wegen einer langwierigen Bindehautentzündung mit lästigem Thränenträufeln consultirte, bestand eine bandartige Brücke von der Breite einer Linie zwischen beiden Augenlidrändern in der Nähe des inneren Winkels, genau so gelagert, dass beide Thränenpünktchen sich ausserhalb derselben befanden. Der innere Winkel war dadurch in eine rundliche Ocfinung verwandelt, in welcher die 'Thränencarunkel sichtbar war. Die Bewegung der Augenlider war kaum beeinträchtigt, die Funktion der übrigens unversehrten Thrinenpünktehen aber vollständig aufgehoben. Das Uebel währte angeblich schon viele 
Jahre, das Thränenträufeln nämlich; denn von der abnormen Verwachsung hatte die Frau gar keine Ahnung. Da die Brücke aus eincr weisslichen, dünnen Membran ohne sichtbare Gefässentwickelung bestand, so trennte ich dieselbe mit der Scheere, trug sic bis zur Basis ab, und cauterisirte die kaum blutenden Schnittrïnder sogleich mit Kupfervitriol. Die Vernarbung erfolgte ohne Wiederverwachsung, und das Thränentrüufeln war gehoben.

5) Wiedereröffnung der rerwaclisenen Thränenpünlitchen.

$J$ üngken operirte vor längerer Zeit ein verwachscnes Thränenpünktchen in der Art, dass er die verschlossene Stelle bis zum Sichtbarwerden des Kanälchens abtrug, Anfangs eine Schweineborste und dann cinen feinen Bleidrath einlegte. Das Kanälchen blieb offen und die Aufsaugung der 'Thränen stellte sich wieder ein. Dieses Verfahren scheint indessen kaum Nachalimer gefunden zu haben. In neucrer Zeit vereinfachte $130 \mathrm{wm}$ an das Verfahren dadurch, dass or sich auf eine cinfache Spaltung des Kanälchens von der verschlossenen Mündung aus auf der Bindehautfäche beschränkte. Nach seiner Versicherung soll die Spalte auch ohne $\Lambda$ nwendung irgend cines Mittels gar keine Neigung zum Schliessen zeigen, und der Zweck auf diese einfache Weise sicher erreicht werden.

Im vorigen Jahle operirte ich einen 24jährigen Mann an Ectropium sarcomatosum der beiden unteren Augenlider, welches seit den ersten Lebensjahren bestanden hatte. Als die Augenlider ihre normale Stellung wieder crlangt hatten, dauerte indessen das lästige Thränenträufeln unverändert fort, indem die Thränenpünktchen so vollständig obliterirt waren, dass sie nur bei starlker Anspannung der Augenlieder auf der glänzenden trockemen Fläche durch eine kaum merkliche Verticfung an- 
gedentet erschienen. Da auch die feinste Sonde vergebens versucht wurde, so entschloss ich mich, nach der Methode von Bowman versuchsweise ein Auge zu operiren. Mit einer äusserst spitzen Scheere drang ich in die fest verwachsene Stclle ein, beschränkte mich jedoch nicht auf cine einfache Spaltung, sondern trug nach beiden Seiten ein kleines Stückehen ab, so dass sich eine winkelfürmige, klaffende Wunde bildete, in welche das Thränenröhrchen ausmündete. Nach einigen Tagen hatte sich die Wunde in eine kleine rundliche Verticfung umgewandelt. Eine Anel'sche Sonde lronnte ohne Widerstand in das Kanälchen eingeführt werden, und die Thränenleitung kam wieder in Gang. Nach 8 Tagen wurde die Operation auch an dem anderen Auge mit demselben Erfolge ausgeführt.

Im vcrflossenen Winter hatte ich Gelegenheit, mich von dem überraschenden Erfolge dieses Verfahrens in einem anderen Falle zu überzeugen. Bei einem älteren Manne waren die beiden unteren, nebst dem oberen Tränenpünktchen des rechten Auges, fast spurlos verschwunden in Folge langwieriger Entzündungen. Die in oben beschriebener Woise verrichtete Operation hatte an dem rechten Auge cinen vollständigen Erfolg, so dass der als Strassenarbeiter beschäftigte Mann seinen Beruf bei der schlimmsten Witterung ausüben konnte, ohne wie früher von Thrämenträufeln belästigt $\mathrm{zu}$ werden. $\Lambda \mathrm{n}$ dem linken Auge bestand das Thränentrïufeln ganz unverändert fort, wiewohl auch hier das Kanalchen sich nicht wieder geschlosson hatte. Wegen einer kleinen Eirhöhung in der Conjunctiva unterhalb des Thränenpünktchens konnte sich dieses nicht gehörig an den Augapfel anlegen, so das es ausser dem Bereiche des Thränensces blieb. Als die warzenartige Erhöhung abgetragen war, lrörte der Uebelstand auf, und das Thräträufeln rerschwand vollständig. Die wiedereröffneten 
Thränenpünktchen verhalten sich den normalen so ähnlich, dass kaum eine Spur der stattgefundenen Operation $\mathrm{zu}$ entdecken ist.

II. Behandlung des Entropiums durch Ligatur, ohne Ausschneidung eines Hautstückes.

Die grosse Menge der gegen das Entropium empfohlenen Operationsmethoden beweist wohl am sichersten, dass die wenigsten derselben ihrem Zwecke vollkommen entsprechen, noch weniger aber in allen Fällen geeignet sein können. Indem ich hier vorzugsweise das seit Himly fast allgemein von abnormer Contraction der Ciliarportion des Orbicularmuskels abgeleitete, sogenannte Entropium spasmodicum berücksichtige, halte ich es für unumgänglich nothwendig, die Genesis dieses Uebels zunächst zu erörtern. Wenn das dem Augapfel genau angepasste Lid durch gleichmässige Wirkung der unter der Cutis gelagerten Muskelschicht in seiner entsprechenden Lage erhalten wird, so muss diese cine $\mathrm{Ab}$ änderung erleiden, sobald der Mechanismus durch einseitige Contraction einzelner Muskelpartieen zerstürt wird. Die ziemlich widerstandslose innere Fläche muss nothwendig stellenweise dem ungleichmässig verstärkten Zuge nach aussen folgen, und zwar aus mechanischen Gründen um so leichter, je näher die Zusammenzichung nach dem Tarsalrande zu stattfindet. Eine Verkürzung der äusseren Hautbedeckung an dieser Stelle hat bekanntlich ein Abstehen des Tarsalrandes vom Augapfel zur Folge, wie man nach schlecht vernarbten Wunden, besonders Brandwunden, nicht selten beobachtet. Eine ganz gleiche Wirkung ruft die einseitige Contraction der Ciliarportion des Orbicularmuskels hervor. Geringere Grade der auf diese Wcise bedingten Ectropien tretcn, wie Blasberg sehr naturgetreu beobachtet hat, dann erst 
hervor, wenn der Kranke das Auge stark schliesst, und fast alle werden unter solchen Lmständen auffallender. Eine ganz entgegengesetzte Wirkung stellt sich ein, wenn die dem sogenannten Musculus ciliaris zunächst liegende Faserpartie in eine stärkere Contraction versetzt wird. Die vor der eingeschnürten Stelle befindliche, relativ erschlaffte, nach $\mathrm{Cruveilhier}$ und Cloquet an sich schwächere, aus bleicheren Fasern bestehende Ciliarpartie wird untcr solchen Umständen das Lid um so weniger in seiner normalen Stellung zu erhalten vermögen, je mehr zugleich die äusseren Hautbedeckungen erschlafft sind. Der Neigung, sich nach einwärts zu kehren, wird übrigens am oberen Lide theils durch den Tarsus, theils durch den Zug des Levator bis auf einen gewissen Grad entgegengewirkt. An dem unteren Lide, wo beide Bedingungen fehlen (ein eigentlicher Knorpel existirt hier wenigstens nicht), kommt darum das Entropium aus dieser Ursache ungleich leichter zu Stande, als an dem oberen. Die ursprünglich gewöhnlich als Folge verschiedener entzündlicher Affectionen auftretende krampfhafte Zusammenziehung geht, wie in viclen ähnlichen Fällen, z. B. bei dem Strabismus, leicht in dauernde Contractur über, welche sich deshalb auch bei manchen scheinbar ganz anders bedingten Entropien nachweisen lässt. Diese Ansicht, welche ich mir schon seit Jahren, gestützt auf die Resultate der nach der später zu erwähnenden Methode von Gaillard operirten Fälle, vom Entropium gebildet habe, fand ich mit einigen Modificationen auch von Vauquelin, de l'application de la suture enchevillée à l'općration de l'entropion spasmodique au moyen d'une nouvelle espèce de cheville (cheville jumelle ou à double branche), Paris 1853, ausgesprochen. V a uquelin hält die Bewegung der Ciliarpartie für unwillkürlich, und leitet die Finwärtskehrung des Tarsalrandes von der durch die Contraction der Orbicularpartic Archiv für Ophthaln. I. 2. 
bedingten Wölbung des Tarsus nach aussen ab. Für crstere Ansicht spricht aber weder ein anatomischer, noch

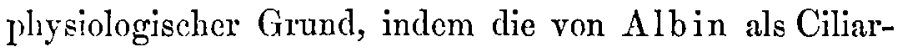
muskel betrachtete Ciliarpartie nur eine weitere Verbreitung eines und desselben Muskels ist, und keine eigenen Nerven erhält. Letztere Ansicht verliert aber schon dadurch an Bedeutung, dass das Entropium, wie schon erwähnt, gerade am unteren Lide am häufigsten vorkommt.

Nachdem ich das Entropium nach den verschiedensten Methoden mit abwechselndem Erfolge operirt hatte, wurde ich auf das Verfahren von Gaillard aufmerksam, welches ich seit mehreren Jahren vielfach geübt habe. Gaillard sticht in der Nähe des inneren Augenwinkels eine mit einem gewichsten Faden versehene Nadel in den M. orbicularis ein, und 2 Centimeter tiefer wieder heraus, schliesst dann dic Ligatur, wodurch der Ein- und Ausstichspunkt genähert, und der Augenlidrand etwas nach auswärts gezogen wird. Fin anderer Faden wird eben so am äusseren Winkel angelegt. Die Ligaturen schneiden ein, comprimiren das Muskelgewebe, und unter der Narbe bilclet sich ein Band, welches das Lid in der erwähnten Stellung erhält. Nach diesen, im Bulletin de la société méd. de Poiticrs, 1844, mitgetheilten Angaben, versuchte ich die Operation zuerst bei einer Frau, bei welcher ich bereits den Orbicularmuskel subcutan an zarei Stcllen durchschnitten hatte. Als sich die schr starke Sugillation verloren hatte, zeigte sich die Stellung des Lidrandes nur wenig verbessert, und nach wenigen Tagen war keine Einwirkung von der Muskeldurchschneidung mehr zu entdecken. Genau nach der Angabe von Gaillard führte ich die Fäden an beiden Winkeln ein, bemerkte aber, dass sich nach dem $\mathrm{Zu}$ sammenschnüren der Ligaturen der Lidrand in der Mitte nur wenig vom Augapfel entfernte, weshalb ich hier noch 
einen dritten Faden einlegte. Am dritten Tage wurden die Faden, welche nur wenig eingeschnitten hatten, entfernt. Die Stellung des Lides war normal. An den Ein - und $\Lambda$ usstichspunkten hatten sich knotige Wülste gebildct, welche durch einen harten Streifen communicirten. Nach acht Tagen hatte sich das Augenlid so geglïttet, dass die Wülste nur noch bei starker Anspannung der Ilaut sichtbar waren, und nach cinigen Wochen war die Anfangs sehr auffallende Röthe an den Stichpunkten spurlos verschwunden.

In dicser Weise habe ich die Operation bei achtzehn Personen, bei mehreren an beiden Augenlidern und Augen, vorgenommen, und weit günstigere Resultate erhalten, als bei den frühcr nach anderen Methoden Operirten. Die einzige Schwierigkeit besteht nur darin, die Nadel so ticf einzuführen, dass Fasern des Orbicularmuskels sicher gefasst werden. Aufangs schob ich eine $J$ ia g er'sche Platte unter das Lid, fand aber, dass diese mehr hinderlich als fürderlich war. Am besten fasst man eine Hautfalte möglichst tief mit einer von einem Gehülfen gehaltenen Schicberpincette, unter welcher man die Nadel durchführt., Mehrmals habe ich sogar die Nadel, ohne cine Itautfalte zu bilden, mit gleich gutem Erfolge durchgestochen, wobei ich die Haut mit der Fingerspitze der anderen Hand der Nadel entgegendrückte. $\Lambda$ nfängein möchte ich dieses Verfahren jedoch nicht empfehlen. Den Einstich mache ich stets etwa eine Linie vom Tarsalrande entfernt. Wällt man diejenige Stelle, an welcher das Lid vorzugsweise einwärts gekehrt ist, so wird der Erfolg am sichersten. Ein Faden genügte niemals, aber mehr als drei fand ich nie nöthig. Je stärker das Lid einwärts gekehrt ist, um so grösser muss der $A$ bstand zwischen dem Ein- und Ausstich sein. Ziemlich schmerzhaft ist das Zuschnüren der Ligatur, welches mit einiger Gewalt geschehen muss, 
daunit eine Verwachsung der gefassten Muskelpartic mit den Lingebungen eintreten könne, von welcher der Erfolg abhängt. Finer zu starken Anschwellung beugt man am sichersten durch kalte Fomentationen vor. Recidive habe ich zweimal, in einem Falle nach zwei Jahren, in dem anderen nach einem Monate, eintreten sehen. Wahrscheinlich war in diesen Fällen der Muskel nicht gehörig von der Ligatur gefasst worden. Bcide wurden auf die gleiche Weise wiederholt behandelt und hergestellt. Einen ganz ungenügenden Erfolg zeigte das Verfahren nur in einem Falle, und zwar bei einer 24jührigen Dienstmagd, welche fünf Jahre zuvor an dem rechten Auge durch dieselbe Operation so glücklich von einem Entropium und dadurch unterhaltenen Pannus befreit worden war, dass sie aus der Blindenanstalt ontlassen werden konnte, worin sie sich bereits längere Zeit befand. An dem unteren Lide des seit vielen Jahren durch Hornhantvereiterung erblindeten linken $\Lambda$ uges hatte sich ein Entropium entwickelt, wolches eine sich auch auf das andere übertragende Reizung unterhielt. An dem früher operirten Auge waren nur bei starker Anspannung der Haut die Stichpunkte durch ihre weissliche Farbe zu erkennen. Die Stellung des Augenlides war eine ganz normale, die Hornhaut vollkommen durchsichtig geblieben. Bei der zweiten Operation zeigte die Person eine so lindische Widerspenstigkeit, dass sie von mehreren Gehülfen kaumgehalten werden konnte, und eine gehörige $\Lambda$ pplication der Suturen ganz unmöglich war. Ich habe selbst Kinder nach dieser Methode operirt, ohne je ein ähnliches Benehmen beobachtet zu haben.

Lange vor Gaillard machte Wardrop eine ganz ähnliche, aber wenig beachtete Operationsmethode des Entropiums bekannt, welche nach Himly (Die Krankheiten und Missbildungen des menschlichen Auges und deren Heilung. Berlin 1843. Bd. I. S. 128.) darin be- 
steht, dass ein Faden 1 Zoll weit unter der Haut bis zur Wurzel des Tarsns durchgeführt, und die Haut mit der Ligatur zusammengeschnürt wird, um Lintzündung, Erguss plastischer Lymphe, und dadurch Aenderung der Richtung mit Verkürzung des Augenlides zu bewirken. Nach ciner Mittheilung in Froriep's Notizen (Bd. 18. Nr.12. 1827. S. 192 aus the Lancet. 1827. Nr.202. p.480) legt aber Wardrop eine Nadel statt eimes Fadens ein, welche cr aussen mit einer Ligatur umgibt, so dass diese dic Haut zusammenzieht, ohne die Blutcirculation darin zu hindern. Jedenfalls ist die Grundidee dieselbe, wie die von Gaillard, dessen Operationsmethode merkwürdiger Weise von scinem Landsmanne Vauquelin ignorirt worden ist, der uns dafür in seiner Nicuerungssucht mit einem äusserst complicirten, fast in eine Spiclerei ausgearteten Verfahren beglückt hat. Mit einer krummen Nadel durchsticht er dic mit einer Pincette aufgehobene Haut, nebst den Fasern des Orbicularnuskels, von oben nach unten, nachdem dic auszuschncidende Partie mit Tinte bezeichnet worden ist. In der Schlinge des mit beiden Enden durch die Nadel gezogenen Fadens befindet sich eine Stallperle eingefädelt. Sind in einem entsprechenden Abstande in dieser W cise zwci Fädon eingelegt, so wird eine feine, etwas abgelaürzte, fest zusammengedrückte, dem Tarsalrande entsprechend gekrümmte IIarnadel horizontal so aufgelegt, dass die Stahlperlen, durch Anziehen des Fadens, zwischen deren Branchen festgehalten werden. Nach Entfernung der Nadel wird das eine Ende des aus der unteren Stichöffnung hervorragenden Doppelfadens auf beiden Seiten durch eine andere Stahlperle gezogen, cine zwcite IIaarnadel gleich der ersten befestigt, und dann die Zusammenschnürung des Hauptstücks zwisehen beiden Haarnadeln durch cinen einfachen Knoten bewirkt, worauf dieses mit einer Scheere abgetragen wird. Da 
die beiden Fäden unter den Haarnadeln liegen, so lrünnen sie durch den Schnitt nicht getrennt werden. Am vierten Tage. werden sie nebst den Haarnadeln entfernt. Dies ist die Suture enchevillée, deren Hauptvortheil darin bestehen soll, dass die fast unblutige Operation eine lineare Vereinigung der Wunde bewirke. An Leichen habe ich diese sehr umständliche Operation einigemal in Gegenwart meiner Zuhürer vorgenommen, und mich von deren Ausführbarkeit überzeugt. An Lebenden werde ich sie aber nie in Anwendung bringen, da die einfache Ligatur ohne Ausschneidung eines Hautstückes in dafür gecigneten Fällen allen Anforderungen entspricht. Noch weniger empfehlungswerth ist das auf gleichem Prinzip beruhende Verfahren von Florent Cunier, welcher die in eine Falte aufgehobene Haut, nebst den Fasern des Orbicularmuskels, mit drei bis vier Insektennadeln durchsticht, diese durch achterförmig umwundene Fäden umschnürt, die Vorsprünge der Haut in den 8 abträgt, so dass sich eben so viele am Muskel hängende Narbenstreifen bilden, als Nadeln eingesenkt worden sind. An dem Erfolge dieses Verfahrens ist kaum zu zweifeln, doch muss nothwendig eine beträchtliche Entstellung zurückbleiben. Das von Winn (Med. Times and Gaz. 1853. Jul. 24.) empfohlene Collodium habe ich schon seit langer Zeit (Schweizerische Zeitschrift für Medicin u. s. w. 1849. H. 3. S. 320) als Palliativmittel - angewendet.

III. Modification der Canthoplastik.

Als ich das erste Mal bei Verengerung der Lidspalte die Canthoplastik vornahm, verfuhr ich nach v. Ammon mit der von Adelmann angegebenen Modification, wobei der von der Sclerotica abgelöste winkclförmige Bindehautlappen mit der Zellgewebefläche in die 
Wunde eingeheftet wurde. Die Operation gclang ohne Schwierigkeit, und dic Vereinigung erfolgte so vollständig, dass im äusseren Winkel der Verlust der Cilien das einzige Auffallende war, so lange der Kranke das Auge in der Mitte fixirt hielt, oder nach auswärts richtete. Wurde dasselbe jedoch stark nach einwärts gestellt, so zeigte sich eine beträchtliche Spannung der in Form einer Falte hervorstehenden und, wic es schien, nicht mit den unterliegenden Theilen fest verwachsenen Bindehaut. Allmählig verminderte sich zwar diese Falte durch Ausdehnung, so dass sie weniger vom Augapfel nach dem äusseren Winkel zu absprang, verlor sich jedoch nach Jahren nic völlig. Bei späteren Operationen änderte ich das Verfahren dahin ab, dass ich den überzupflanzenden Lappen nicht vom Augapfel, sondern dicht an demselben aus der Bindehautfalte ablüste, welche hinlängliche Dehnbarkeit darbietet, um ohne starke Zerrung in den Wundwinkel geheftet zu werden. Am leichtesten geht dies, wenn man die Bindehaut dem Winkel müglichst nahe mit einer Zahnpincette fasst, mit cinem spitzen Bistouri winkelförmig ablöst, und ohne die Pincette loszulassen, sogleich cine eingefädelte Nadel neben dicser durch die Spitze des Lappens und durch die Hantbedeckungen am frisch gebildeten äusseren Augenwinkel führt. Ist diese Ligatur zugezogen, so lassen sich die Seitentheile des Bindehautlappens schr leicht in ähnlicher Weise mit den Wundrändern vereinigen, wozu immer zwei Hefte genügen. Am dritten Tage können diese entfernt werden. Ich sah stets vollständige Vereinigung erfolgen. Eine Entstellung nach dieser Operation bleibt nicht zurück, die Bewegungen des Auges sind ganz frei, und eine Faltung des eingehültten Bindehautlappens nach dem Augapfel zu ist nicht zu bemerken. 
IV. Bemerkungen über die künstliche Pupillenbildung.

Es ist nicht meine Absicht, hier in eine nähere Schilderung dieser Operation einzugehen, über welche ich mich in meiner Schrift über die Krankheiten und Bildungsfehler der Regenbogenhaut, 2. Abtheilung, S. 169 - 219, ausfübrlich verbreitet habe. Ich werde mich vielmehr darauf bcschränken, auf einzelne bemerkenswerthe Ereignisse hinzuweisen, welche ich bei dieser sehr häufig verrichteten Operation beobachtet habe.

Die Iridectomie ziehe ich überall vor, wo sie überhaupt ausführbar ist, und verrichte sie öfters unter Verhältnissen mit Erfolg, wo Andere in der Regel dio Iridodialysis wählen. Eine traumatische Reaction ist mir unter einer grossen Zahl von Füllen nur ein einziges Mal vorgekommen, und zwar ohne Beeinträchtigung des Resultates, so dass in der Regel eine rein negative Nachbehandlung vollkommen genügte. Der Grund dieser Anfangs allerdings befremdenden Indolenz der sonst so sehr zu Entzündungen geneigten Iris ist ohnc $Z_{w}$ eifel darin zu suchen, dass die bei dieser Operation gewaltsam gezerrto Partie in den $\Lambda$ usschnitt fullt, wobei noch die stets dabei eintretende Blutung in Betracht kommen dürfte. Leider wird die Iridectomie in manchen Fällen hüchst schwierig, oder gar unmöglich, wo sie vollkommen indicirt $z \mathfrak{u}$ sein scheint. Dies liegt in einer eigenthümlichen Veränderung des Irisgewebes, welche sich so wonig vor der Operation durch den blossen Anblick mit Bestimmtheit ermitteln lässt, wie die Consistenz einer Cataracta. Die durch vorausgegangene Entzündungsprozesse alienirte Iris besitzt ofters cine so geringe Dehnbarkeit, dass sie, anstatt dem Zuge des Häkchens oder der Pincette zu folgen, einreisst, oder bei grösserer 
Resistenz sich vom Ciliarligamente ablöst. Beides ist mir mehrfach vorgekommen. Bei einem durch Verletzung mit einem Steinfragmente erblindeten Manne bildete sich bei der versuchten Ausführung der Iridectomie eine sehr grosse Pupille durch unfreiwillig gcübte Iridodialysis, und das Gesicht wurde hergestellt. In einem anderen Falle, bei eincm älteren Manne, welchem ich einen Staar extrahirt hatte, schloss sich dic Pupille durch ein entzündliches Exsudat. Da nach abwärts eine schon länger bestandene IIornhauttrübung zugegen war, so beschloss ich, cine künstliche Pupille in der Mittellinie nach oben durch Iridectomie anzulegen. Es war übrigens unmöglich, eine Falte emporzuziehen, indem das Häkchen ohne Widerstand sogleich einen Einriss verursachte. Ich benutzte diesen Lmstand in Augenblicke, indem ich das Hakkchen bis zum Pupillarrande weiter führte, und diesen selbst trennte. Die Folge war cin augenblickliches Auscinanderweichen des Irisgewebes, wodurch sich eine trianguläre, cinem Colobom ähnliche, fast centrale Pupille mit abwiirts gerichteter Basis bildete. Bevor ich den Operirten am folgenden Morgen besuchen konnte, überraschte mich derselbe in meiner Wohnung, um nir freudig sein wiedererhaltenes Schvermögen zu verkünden. Dieser Unvorsichtigkeit ungeachtet trat nicht die mindeste Reaction ein, die Schenkel der Pupille rundeten sich nach einigen Tagen etwas ab, und Patient sah später mit ciner Staarbrille so gut, dass er lesen konnte. Leider sind dies aber nur Ausnahmsfälle, da in der Regel unter solchen Limständen die Operation misslingt. Mehrfach habe ich bei mangelnder Dehnbarkeit des Irisgewebes versucht, mit einer feinen Pincette cine Wunde mit Substanzverlust zu bilden, ohne jemals einen Erfolg zu crzielen. Die Oeffnung zeigte sich jedesmal verschlossen, nachdem das Blutextravasat resorbirt war. In anderen Fallen mag dieses Dechirement de l'iris nach Demaries 
gelingen, ist aber dann sicher auch durch die weit weniger verletzende Iridectomic zu ersetzen.

Ist die vordere Augenkammer durch Vordrängung der Iris so verengert, dass die Einführung eines Instruments zwischen dieser und der Hornhaut unmöglich wird, so lässt sich die Iridectomic gleichwohl ausführen, ohne dass man genöthigt wäre, durch die Sclcrotica einzugehen. In solchen Fällen nehme ich keinen Anstand, die Iris nahe am Rande zugleich mit der Hornhaut zu perforiren, ein Häkchen einzuführen, und damit in der hinteren Augenkammer bis zu der Stelle vorzudringen, wo die Pupille angelegt werden soll. Die von hinten gefasste Iris wird durch die Wundöffnung hervorgezogen, und wie gewöhnlich ausserhalb derselben mit der Scheere abgetragen. In verschiedenen Fällen habe ich auf diese Weise mit Glüıck operirt, ohne jemals eine stärkere Reaction beobachtet zu haben. Finer leicht möglichen Verletzung der Linsenkapsel beugt man sicher vor, wenn man das flach gehaltene Häkchen dicht an der Uvea vorschiebt.

Bei gleichzeitiger Cataracta, wenn diese mit Bestimmtheit vor der Operation zu diagnosticiren war, habe ich einige Mal die Iridectomic nach Jüngken's Modification der Wenzcl'schen Methode mit der Extraction verbunden. Das nahe am Hornhautrande eingestochene Staarmesser wird dann nur wenig vorgeschoben, in dio Iris eingesenkt, beim Weiterführen an der entgegengesetzten Seite aus der Iris, und dann an der gewöhnlichen Stelle durch die Hornhaut ausgeführt. Bei der Vollendung des Hornhautschnittes bildet sich zugleich ein halbrunder Irislappen, durch welchen die nebst der Kapsel zerschnittene Linse leicht austritt. Anstatt den Hornhautlappen umzuschlagen, wie $\mathrm{J} u ̈ n g k$ en angiebt, führe ich eine feine Pincette unter denselben cin, ziehe den Irislappen hervor, und trage ein Stückchen mit der Scheere ab, Bei einer dieser Operationen hat mir Herr 
Dr. Pauli aus Landau vor viclen Jahren assistirt, welcher sich von der Leichtigkeit der Ausführung überzeugte. Gleichwohl war ich mit den Resultaten nicht zufrieden, indem sich ziemlich unregelmässige, bei dem stets nach unten verübten Hornhautschnitte dem Ciliarrande zu nahe stehende Pupillen bildeten, welche überdies leicht noch durch die Schnitnarbe etwas beschränkt werden. Da ich complicirte Instrumente nicht liebe, so habe ich mit Stromeyer's Corectom noch keinen Versuch gemacht. In späteren Fälen übte ich die Iridectomic in gewöhnlicher Weise, riss die Linsenkapsel nach Zurückschiebung der gewöhnlich in der Hornhautwunde hängen bleibenden Irispartie mit der Spitze des wieder eingeführten Häkchens in mehreren Richtungen cin, und schritt erst später zur Reclination des Staars durch die Sclerotica, wenn die Resorption nicht, oder doch zu langsam erfolgte. Bei einem scrophulösen, an cinem Auge durch Totalstaphylom der Hornhaut erblindeten Mädchen sah ich mich genöthigt, wegen gänzlicher 'Trübung' der oberen Hälfte der Iornhaut mit Pupillensperre, eine künstliche Pupille nach unten anzulegen. Als nach Resorption des bedeutenden Blutextravasats die sehr grosse Pupille zum Vorschein kam, lag cine nicht vermuthete Cataracta dahinter. Ich versuchte in diesem Falle die Sublatio cataractae, nach Pauli, durch die künstliche Pupille. Die Operation misslang aber wegen Adhäsionen am oberen Pupillarrande, welche ich nicht zu lösen im Stande war. Nach einer mehrtägigen Pause reclinirte ich endlich den Staar nach Lösung der Verwachsungen durch die Sclerotica mit bestem Erfolge. Den umgelegten Staar sah man sehr deutlich im Augangrunde liegen, so lange ich die auswärts wohnende Patientin beobachten konnte. Sie wurde sehend entlassen, soll aber später durch eine neue Entzündung wieder erblindet sein. 
Dass die für gewöhnlich ganz gleichgültigen Blutextravasate, welche in der Regel schon nach 24 Stunden verschwunden sind, bisweilen hartnäckig längore Zeit der Resorption widerstehen, habe ich einige Mal wahrgenommen. In einem Falle dauerte es gegen vier Wochen, bis die Pupille frei wurde, ohne dass irgend ein in der Individualität liegender Grund bei einer jungen kräftigen Frau zu ermitteln war. In einem anderen Falle zeigten sich nach der Resorption des Blutextravasats die Pupillarränder mit flockigen Franzen besãumt, welche nur in der Mitte eine kleine Stelle frei liessen, wodurch Patient ziemlich gut sah. Ja selbst Wiederverschliessung der durch Substanzverlust gebildeten Sehöffnung ist mir unter solchen Verhältnissen vorgekommen.

Eine andere eigenthümliche Erscheinung, die $\Lambda \mathrm{n}$ füllung der Pupille mit dicht zusammengedrängten, weisslichen Flöckchen, ohne Adhäsion mit deren Rändern, habe ich bei zwei Patienten, bei beiden längere Zeit nach der glücklich vollzogenen Operation, eintrcten schen, so dass das Anfangs gute Gesicht cine bedeutende Beeinträchtigung erlitt. Ein neapolitanischer Soldat verlor das eine Auge durch eine gonorrhoische Ophthalmoblennorrhöe, und wurde, am anderen durch vollkommene Pupillensperre und gleichzeitigen Pannus erblindet, nach längerer Behandlung in den Militärspitälern als Invalide entlassen. In die Schweiz zurückgekehrt, mehrere Monate lang in einem augenärztlichen Institute behandelt, wandte er sich später an mich, mit dem schriftlichen Zeugnisse der Unheilbarkeit seines Uẹbels versehen. Nach mehrmonatlicher Behandlung gelang es mir, den partiellen Pannus zu beseitigen, und die Reizung des Auges so zu beschwichtigen, dass ich cine Operation wagen zu dürfen glaubtc. Durch Iridectomie legte ich eine Pupille mit solchem Erfolgo an, dass Patient bei seiner Entlassung nicht blos den Rückweg ohne Führer 
zu Fuss antrat, sondern selbst grobe Druckschrift zu lesen vermochte. Eine Mirnerschütterung, wolche bald nach der Operation durch den Sturz in einen Keller entstanden war, ging ohne üble Folgen vorüber. Ein Jahr später fand sich der Operirte wegen bedentender Verminderung der Sehliraft wieder bei mir ein. Die offen geblicbene, grosse l'upille war mit den oben erwähnten weisslichen Flückchen gefüllt, welche ich, da dus Auge übrigens in normalem Zustande geblieben war, durch Fxtraction mit ciner Pincette zu entfernen beabsichtigte. Kaum hatte ich einen Hornhautschnitt gebildet, als sich zu meinem und der anwesenden Studirenden Erstamen die Flöckchen in Bewegung sctzten, in die vordcre Kammer senkten, und grossentheils mit dem Humor aqueus abflossen, so dass ich blos einige derselben mit der l'incette zu entfernen nöthig hatte, um die Pupille ganz rein zu machen. Das Gicsicht besserte sich augenblicklich, und nach zwei Jahren hatte ich Gelegenheit, mich von dem dauernden Erfolge zu überzeugen. Leider habe ich über die Natur der die Pupille ausfüllenden Massen keinen Aufschluss erhalten. Die mit dem IIumor aqueus abgeflossenen Partieen konnten nicht untersucht worden. Krystallinisch schienen dieselben nicht zu sein. Kwischen den Branchen der Pincette drückten sie sich in eine unkenutliche weiche Masse zusammen.

Einige Jahre später bot sich mir Gelegenheit dar, cine ganz ähnliche Wahrnehmung an einem, durch eine variolöse Ophthalmie erblindeten jungen Manne zu machen, welchem ich durch Iridectomie eine Pupille angelegt hatte. Das Anfangs ziemlich gute Gesicht nahm allmälhlig ab, inden sich dic Pupille, wie im ersten Falle, mit weisslichen Flöckchen füllte, ohne dass eine traumatische Reaction bemellbar gewesen wäre. Gestützt auf das glücliche Resultat in dem vorigen Falle, unternahm ich auch hier eine zweite Operation, um die Exsudate 
zu entfernen. Ein freiwilliges Austreten aus der Pupille bei dem Ausflusse des Humor aqueus erfolgte jedoch so wenig, dass ich genöthigt war, die unter sich nur locker verbundenen Flöckchen, wie es schien, eiwcissstoffige Exsudate, cinzeln mit der Pincette wegzunehmen. Die Pupille wurde gleich nach der Operation nicht ganz rein, doch schwanden die zurückgebliebenen, etwas beweglichen Kürperchen während einiger Wochen so vollständig, dass der am anderen Auge durch ein Hornhautstaphylom erblindete Patient seinen Beruf als Schirmfabrikant wieder auszuüben im Stande war.

Zum Hervorziehen der Iris bei der Iridectomie bediene ich mich stets eines einfachen Häkchens. Den Hornhautschnitt bilde ich nur so gross, dass das Häkchen mit Leichtigkeit ein- und ausgeführt werden kann, und zwar in der Absicht, den Abfluss des Humor aqueus möglichst zu verhüten. Auf diese Weise gewinne ich freieren Raum zur Führung des Häkchens, da sich die Iris nicht, oder doch nur wenig vordrängt. Ohne Schwicrigkeit lässt sich das Häkchen bis zu derjenigen Stellc führen, wo die Pupille gebildet werden soll, welche ich in der Regel so anlege, dass sie von dem Hornhautschnitte etwas entfernt bleibt. Mehrfach ist es mir gelungen, fast centrale Pupillen zu erzielen, was bei Anwendung der Pincette minder leicht müglich ist. Wird letztere zum Hervorziehen der Iris benutzt, so ist man genöthigt, einen grösseren Hornhautschnitt zu machen, da man auf eine Vordrängung der Iris nach dem $\Lambda b-$ flusse der wässcrigen Feuchtigkeit rechnen muss. In der Regel ist aber dann der Uebelstand nicht zu vermeiden, dass dic Pupillen mohr oder weniger peripherisch werden, wenn sie auch gross genug ausfallen. Mögen auch die erwähnten Vorzüge des Häkchens zum Theil nur individueller Natur sein, indem sie durch eine grüssere Fertigkeit mit diesem Instrument crklärt werden 
künnen, so schlage ish sie doch so hoch an, dass ich mich der Pincette zu dem erwilhnten Zwecke gar nicht mohr bediene, ohne in Abrede stellen zu wollen, dass Andere mit dieser nicht minder glüekliche Frfolge erziclen liünnen.

Die Iridodialysis habe ich verhältnissmässig sclten vorgenommen, da ich sie grundsätzlich auf diejenigen Fialle beschränkte, in welchen keine andere Operationsmethode ausführbar ist. Niemals habe ich mich auf die blosse Ablüsung der Iris von dem Ciliarligamente beschränkt, sondern stets die Einklemmung, wo müglich dic Ausschneidung der Spitze des vorgezogenen Iristheils damit verbunden. Im Vergleiche mit der Iridectomie liefert sie stets geringe Resultate, da das Gesicht, wcgen des Einfallens der Lichtstrahlen durch den minder brechenden Linsenrand, auf einen Seitentheil der Netzhaut fast nie gehörig scharf wird. Auf dic Beobachtung gestützt, dass Personen, bei welchen nach unglücklich abgelaufener Staaroperation die Iridodialysis vorgenommen wurde, durch eine Staarbrille verhältnissmässig gut sahen, versuchte ich schon längst auch bei unversehrtem Iinsensystem schwache Convexgläser. In dem zwciten Theile meiner Schrift über die Kranliheiten der Regenbogenhaut (Bern 1845, S. 215), habe ich den Nutzen dereits erwälnt. Win Jahr spater empfahl Trinchinetti (Gaz. med. di Milano. Jan. 1846) die Convexglïser als ein noucs Mittel zur: Verbesserung des Gesichts bei peripherischen Pupillen.

Die Wiederherstellung der fast allgemein nur auf den einzigen seltenen Fall des Zurückbleibens der Pupillarmembran bezogenen natürlichen Pupille, wclcher ich a. a. O. S. 179-182 eine Stclle unter den übrigen Operationsmethoden zu vindiciren versucht habe, ist, was wenig bekannt zu scin scheint, schon von Woolhouse angeregt worden. Dieser machte nämlich den Vorschlag, 
die Pseudomembran von der hinteren Augenkammer aus mit ciner gewöhnlichen Staarmadel einzuschneiden, um die Lichtleitung horzustellen. Fast ganz unbeachtet geblieben, ist die Operation früher, meines Wissens, blos von Henkel und Siemerling, später ausser mir von Silvy und Laugier ausgeführt worden. In der That hat auch diese Methode wenig $\Lambda$ nziehendes, da sie überall durch andere Verfahrungsweisen umgangen werden kann, und nur unter mehreren, am seltensten vereinten Bedingungen ausführbar ist. Dahin gehört, ausser der sich von selbst verstehenden Durchsichtigkeit des Centrums der Hornhaut, eine Verschliessung der nicht verengerten Pupille in einer gehürig angespannten Iris durch eine Pseudomembran, so wie Abwesenheit der Linsenkapsel und Linse nach vorausgegangener Staaroperation. Dass aber unter diesen Umständen die natürliche Pupille hergestellt werden könne, haben fremde und eigene Versuche gelehrt. Vor mindestens zwölf Jahren vollzog ich die erste Operation in der Art, dass ich mit einer durch die Hornhaut eingeführten Gräfe'schen Sichelnadel dic Pscudomembran durch verschiedene, im Mittelpunkte sich durchlrreuzende Schnitte trennte, und die Pupille durch kalte, mit Belladonnaextrakt versetzte Fomentationen elweiterte. Die Anfangs unregelmässige Oeffnung vergrösserte sich so, dass Patient, ungeachtet der am Pupillarrande zurückgebliebenen plastischen Lxsudate, ein gutes Gesicht erhielt. Spätcr operirte ich in andercr Weise. Bei einer schwächlichen, höchst torpiden Frau, welche ich mittelst der Reclination durch die Sclerotica an einem Auge glücklich an Cataracta operirt hatte, vollzog ich die gleiche Operation ein Jahr später an dem anderen. Ohne dass in den ersten Wochen eine bemerkenswerthe Reaction eingetreten wäre, schloss sich die Jupille später durch eine ganz schleichend cntstandeno Iritis. Eine weissliche Membran füllte die ziemlich regel- 
mässige, im Zustande mittlerer Weite befindliche Pupille aus, rings mit deren Rändern in so fester Verbindung, dass eine künstliche Erweiterung ummöglich war. Mit einer stark gekrümmten Staarnadel versuchte ich dic Ablösung und Reclination dieser Membran von der hinteren Augenkammer aus, konnte aber nichts weiter crzielen, als diesclbe in einige unregelmässige, wenig klaffende, mit dem Pupillarrande grösstentheils in Verbindung blcibende I,äppchen zu zerreissen. Die Masse war so zähe, dass ein cigentliches Einschneiden mit der zweischneidigen, sehr scharfen Staarnadel unausführbar blieb, nachdem die vollständige Ablösung misslungen war. Die Operation hatte indessen so viel genützt, dass es nach einiger Zeit möglich wurde, die Membran mittelst einer durch einen Ilornhautschnitt eingeführten gekrümmten Zahnpincette zu fassen, und im Zusammenhange zu extrahiren. Dies gelang so vollständig, dass sich an den Rändern der ganz reinen Pupille kaum Spuren von früheren Anheftungen bemerken liessen. Gleichwohl musste es in höchstem Grade überraschen, dass Patientin, welche vor der Pupillenverschliessung sehr gut gesehen hatte, auch keine Spur von Lichtempfindung besass. Aus der etwas gespannten Beschaffenheit des Augapfels, in Verbindung mit der zicmlichen Erweiterung der starren Pupille, auf cine der Iritis vorausgegangene Entzündung und noch fortbestehende Hyperämic der Chorioidea schliessend, schritt ich zur Anwendung von Mercurialien, welche ich bei den ersten Spuren von Auflockerung des Zahnfleisches mit starken Dosen von Jodkali vertauschte. Wider alle Erwartung kehrte das Sehvermögen bei dieser Behandlung so vollkommen zurück, dass Patientin, welche ich ein Jahr später sah, sogar die Staarbrille ablegen konnte.

Eine andere hierher gehörige Operation habe ich erst kürzlich verrichtet. Eine 59jährige Frau vom Lande, 
deren rechtes Auge vor 20 Jahren angeblich zweimal erfolglos an grauem Staar operirt worden war, hatte das Unglück, das Gesicht auch an dem linken vor zwei Jahren vollständig $z u$ verlicren. Ich fand das linke Auge glaucomatös, die verengerte, unregelmässige Pupille des rechten durch eine weiss-gelbliche Membran verschlossen, dic Lichtempfindung an letzterem so beschränkt, dass Patientin kaum mehr als Tag und Nacht unterscheiden konnte, und die Bewegung ihrer Hand nur ganz nahe an dem Fenster wahrnahm. Die etwas schmutzig-grauc Iris war nur an der kleinen Zone in ihrer Structur verändert, indem hicr dic Fasern etwas verwischt erschienen. Das scheinbar etwas verkleinerte Auge zeigte die natürliche Resistenz. Nach Beseitigung einer leichten Bindehantentzündung bildete ich durch Iridectomic einc fast centrale Pupille, welche sich augenblicklich mit einem Blutextravasat füllte. Am Tage nach der Operation war dieses verschwunden, die beinahe kreisrunde Oeffnung aber durch eine unmittelbare Fortsetzung der Pseudomembran verdeckt, welche die natürliche Pupille ausfüllte. Da der seitliche Pupillarrand in den Ausschnitt gefallen war, so communicirte die künstliche Pupille mit der verschlossenen natürlichen. An einer ganz kleinen Stelle nach aussen und oben zeigte sich in der künstlichen Sehüffnung eine schwarze Spalte, durch welche Patientin unverhältnissmässig gut sah, so dass sie eine Schreibfeder, einen Schlüssel erkannte, wenn diese Gegenstände in der Richtung nach innen und unten vorgehalten wurden. Selbst ihre Füsse sah sic im Gehen. Als nach vicrzehn Tagen keine Erweiterung der Spalte durch örtliche Anwendung der Belladonna bewerkstelligt werden konnte, unternahm ich eine zweite Operation, indem ich die hinter der Iris befindliche Membran, welche wohl die durch Exsudatauflagerung unkenntlich gewordene vordere Linsenkapsel sein mochte, 
mit dem Häkchen zu extrahiren versuchte. Als ich dieselbe in der Mitte gefasst hatte, löste sie sich so vollständig ab, dass auch die natürliche Pupille frei wurde und mit der künstlichen zusammenmündete. Bevor ich dic in der etwas klcinen Hornhautöffnung abgestreifte Membran mit der Pincette fassen konnte, musste ich die Operation wegen eines unvermutheten $Z$ wischenfalles beendigen. Der Gehülfe drückte nämlich in diesem Augenblicke mit der Fingerspitze so stark auf den Augapfel, dass eine beträchtliche Menge des zicmlich flüssigen Glaskörpers ausfloss. Das Auge collabirte so stark, dass die trichterförmig eingesunkene Hornhaut mit der Iris in Berührung kam. Glücklicher Weise erlitt aber das Auge dadurch keinen anderen Nachtheil, als dass sich ein schmaler Streif der Membran wieder zurückzog und die sonst sehr schöne Pupille in zwei ungleiche Halften theilte. Das Gesicht hatte sich zwar verhältnissmässig wieder gebessert, doch klagte Patientin über einen fortwährenden Schimmer, wie sie sich ausdrückte, welcher sie hinderte, ohne Führer sich auf die Strasse zu wagen, wiewohl sie angeblich jeden Pflasterstein unterschied. Da dic beiden ersten Operationen nicht die mindeste Reaction, kaum eine vorübergehende Reizung zur Folge hatten, so entschloss ich mich, nach abermals vierzehn Tagen, den Rest der Pseudomembran zu entfernen, was ohne Schwierigkeit gelang, so dass die Pupille nun ganz rein wurde, und kaum von einer natürlichen zu unterscheiden war. Das Gesicht wurde nicht sehr scharf, jedoch in solchem Grade gebessert, dass sich Patientin vor ihrer Abreise allein bei mir verabschieden konnte. Wesentlicher Nutzen dürfte von dem späteren Gebrauche einer Staarbrille zu erwarten sein.

Vielfach ausgeführte Ablüsungen mit Reclination oder Extraction des mit den Pupillarrändern adhärirenden Kapselnachstaares will ich hier unberührt lassen, da sie 
herkümmlicher Weise nicht zu den Pupillenbildungen gerechnet werden. Eine wesentliche Verschiedenheit bieten sie indessen nicht dar, indem der Nutzen dieser Operationen nur auf Wiederherstellung der natürlichen Pupille beruht.

Die künstliche Pupillenbildung gehört, nach meinen zahlreichen Erfahrungen, zu den belohnendsten Augenoperationen, welche vor der Staaroperation den unbestreitbaren Vorzug besitzt, dass sie, mit gehöriger Umsicht und Geschicklichkeit ausgeführt, niemals schaden kann. Ich habe sie niemals auf die günstigsten Fälle beschränkt gleich Beer, Joh. Adam, Schmidt u. A., sondern überall geübt, wo auch nur Wahrscheinlichkeit des Gelingens vorhanden war. Aus diesem Grunde habe ich freilich oft genug keinen Erfolg erhalten, dagegen nicht selten auch die grosse Freude erlebt, Unglücklichen das Gesicht wieder zu verschaffen, welche von anderen Aerzten als unheilbar erklärt waren. Viele von meinen Operirten konnten mittelst der künstlichen $\mathrm{Pu}-$ pillen zu ihren früheren Beschäftigungen zurückkehren, manche minder Glücklicke wenigstens in anderer Weise ihren Unterhalt gewinnen. Ein von mir vor zwrei Jahren durch Iridectomie operirter, durch Ophthalmoblennorrhoea gonorrhoica erblindet gewesener Lithograph musste seinen Beruf aufgeben, konnte jedoch als Handelscommis seither fungiren, und hat sich, wie er mir kürzlich schriftlich meldete, auswärts als Kaufmann etablirt. Kehrt bisweilen auch das Gesicht nur in beschränktem Grade zurück, so beherzige man wenigstens, dass schon ein Lichtschimmer, der die Nacht des Blinden erhellt, von diesem als die grösste Wohlthat begrüsst wird.

Indem ich mich in vorstehenden Bemerkungen, welche ich als reine Ergebnisse meiner Beobachtungen ohne alle theoretische Beimischung mitzutheilen bemüht war, absichtlich der Aufzählung und Schilderung gewöhnlicher 
Operationsfälle enthalten habe, bemerke ich schliesslich nur noch, dass die künstliche Pupillenbildung unter solchen Umständen die glänzendsten Resultate liefert, wo sie bei gesunder Iris wegen Deckung der Pupille durch Centralleukom verrichtet wird.

\section{Cataracta nigra?}

Im November 1852 consultirte mich eine 56jährige robuste Frau wegen völliger Errblindung des linken und bedeutender Gesichtsabnahme des rechten $\Lambda$ uges. Das linke Auge war schon über ein Jahr in dem Grade erblindet, dass Patientin nur noch die Bewegung der Hand gegen das Fenster wahrnehmen konnte, während sie mit dem rechten kaum noch so viel sah, um allein auszugehen. An dem rechten Auge war eine ziemlich weit vorgeschrittene Linsentrübung, mit partiellen Exsudaten auf die vordere Kapsel gemischt, vorhanden, während das linke bei dem ersten $A$ nblick amaurotisch zu sein schien. Die wenig bewegliche, kreisrunde, etwas erweiterte Pupille war schwarz, zeigte jedoch bei genauerer Untersuchung einen ganz eigenthümlichen, matten Schein, der nicht aus dem Augengrunde zu kommen schien. Nach künstlich erweiterter Pupille änderte sich die schwarze Farbe in eine stahlblaue, welche bei der Betrachtung des Auges von der Seite offenbar der Iris ganz nahe liegend, in der Kapsel oder Linse gesucht werden musste. Bei ganz durchsichtiger Hornhaut reflectirte die Pupille das Licht gar nicht. Das Gesicht war durch die Pupillenerweiterung etwas besser geworden, so wie auch Patientin bei beschattetem Auge die Umrisse grösserer Objecte, z. B. ihre vorgehaltene Hand, etwas deutlicher sah. Durch die Loupe liess sich in der Pupille nichts wahrnehmen, was zur Begründung der Diagnose beitragen konnte. Die stahlblaue Trübung 
zeigte keine merklichen Unebenheiten. Line mir bis dahin noch nicht vorgekommene Cataracta nigra vermuthend, suchte ich, damals leider noch nicht im Besitze eines Augenspiegels, durch die Purkinje'schen Lichtbilder Aufschluss zu erhalten. Wiederholte Versuche mit einer brennenden Kerze, wolche ich bei erweiterter Pupille nach verschiedenen Richtungen vor dem Auge hin und her bewegte, bestärkten mich in meiner Vermuthung, indem nur ein aufrecht stehendes Lichtbild zu entdecken war. Ein zufällig anwesender College, so wie verschiedene Studirende, vermochten eben so wenig mehr als das eine Lichtbild wahrzunehmen. Da das Auge übrigens normal war, keine ungewöhnliche Resistenz, noch weniger eine varicöse Beschaffenheit zeigte, so glaubte ich zu einer Operation schreiten zu dürfen, und entschloss mich zur Extraction, um den sichersten Aufschluss über die Richtigkeit der gestellten Diagnose zu gewinnen. In Gegenwart des Herrn Dr. Wittenbach und verschiedener Studirenden wurde die Operation mit dem Hornhautschnitte nach unten vorgenommen. Nach eröffneter Kapsel trat die Linse leicht aus, aber nicht schwarz, wie ich vermuthet hatte, sondern etwas dunkelbernsteinfarbig, mit einzelnen weisslichen Stellen versehen, so dass sie kaum cataractös zu nennen war. Die Pupille hatte wenig von ihrem früheren stahlblauen Ansehen verloren, war jedoch nicht mehr gleichmässig gefärbt. Patientin behauptete, viel deutlichere Lichtempfindung zu haben, wurde jedoch aus Vorsicht keinen anstrengenden Sehversuchen unterworfen, sondern sogleich nach Schliessung der Augenlidspalte mittelst eines mit Collodium bestrichenen Musselinstreifens zu Bett gebracht.

Im ersten Augenblicke war ich kaum im Zweifel, eine falsche Diagnose gestellt zu haben, hegte indessen alsbald die Vermuthung, es möge die zurückgebliebene, 
wahrschcinlich nicht ganz aus dem Bcreiche der Pupille gewichene Linsenkapsel der Sitz ciner krankhaften Pigmentablagerung gewesen sein. Leider sollte ich hierüber keinen ganz befriedigenden Aufschluss erhalten, indem die Pupille, in Folge einer schleichenden Iritis, durch cine weissliche Membran ausgefüllt war, als das Auge untersucht werden konnte. Diese hing nur stellenweise mit den Pupillarrändern zusammen, so dass die Annahme eines Kapselnachstaars die grösste Wahrscheinlichleit für sich hatte. Zwci Monate später nahm ich die Extraction desselben mittelst eines durch cinen Hornhautschnitt cingeführten Häkchens vor, welche leicht von statten ging, und wenigstens einen insofern befriedigenden Erfolg hatte, als Patientin mit dem operirten Auge weit besser sah, als mit dem anderen, wenn auch das Gesicht, wie ich später vernahm, nicht sehr scharf geworden ist. Die Pupille wurde gleich nach der Operation rein schwarz. An der extrahirten Membran war keine Spur einer Pigmentablagerung zu erkennen, welche aber müglicher Weise durch die lymphatische Exsudation verdeckt sein konnte. Für meine Ansicht spricht wenigstens das Resultat der zweiten Operation, wodurch auch die erste als gerechtfertigt erscheinen muss. Eine Cataracta nigra lenticularis war offenbar nicht zugegen. Von Beobachtungen einer ausgebreiteten Pigmentablagerung auf die vordere Linsenkapsel, welche Pauli als das Wesen der Cataracta nigra ansieht, ist mir aber kein Fall bekannt. Dass Uveapigment sich auf die Linsenkapsel abgesetzt habe, wie dies so oft stellenweise nach Ablauf der sogenannten Periphakitis vorkommt, ist mir deshalb unwahrscheinlich, weil nirgends cine Adhäsion mit der Uvea zu bemerken war. Auch entsprach die Färbung durchaus nicht derjenigen, wie sic der sogenannten Cataracta chorioidealis eigen ist. Woher aber dic dunkle Färbung rührte, vermag ich kaum zu ver- 
muthen, da wohl in der Linsenkapsel selbst dic Quelle der Pigmenerzeugung unmöglich gesucht werden kann.

Jedenfalls schien mir dieser hüchst ungewühnliche Fall einer treuen Mittheilung werth zu sein, wäre es auch nur, um auf die Schwierigkeit der angeblich so sicheren Diagnose der Cataracta nigra hinzuweisen.

\section{Operation der angebornen Cataracta.}

Erfüllt von den rührenden Schilderungen der Empfindungen Blindgeborner beim Erschlossenwerden der sichtbaren Welt, unternahm ich die erste Operation eines angebornen grauen Staares, wurde jedoch nicht wenig getäuscht, als ich mich in diesem, wie in späteren Fällen von dem verhältnissmässig geringen Eindruck auf den Operirten überzeugen musste. Bei ganz kleinen Kindern kann man sich in der ersten Zeit nach der gelungensten Operation nur schwer Gewissheit verschaffen, ob dieselben mehr als blosse Lichteindrücke wahrnehmen, und selbst bei älteren Individuen erschliesst sich der Gesichtssinn in der Weise, dass er Anfangs verwirrend wirkt, und nur allmählig durch den Tastsinn eine solche Berichtigung gewinnt, um sichere Eindrücke hervorzurufen. Ueber Grösse und Entfernung der Objecte hat dor sehend gewordene Blindgeborne gar kcin Urtheil, und erlangt dies verhältnissmässig am spätesten, während er sich über die Gestaltverhältnisse der tastbaren Gegenstände ziemlich rasch orientirt, und am schnellsten grell abstechende Farben unterscheiden lernt. Diese Veränderungen erfolgen sämmtlich so allmählig, dass das Ueberraschende grossentheils wegfällt, wenn es freilich auch immer höchst interessant bleibt, die fortschreitende Entwickelung des Gesichtssinnes und dessen Einfluss auf die ganze Individualität, Gang, Gesichtsausdruck, und vor Allem auf das geistige Leben in 
Folge der unmittelbaren Anschauung der Aussenwelt zu beobachten.

Die Staaroperation bei Blindgebornen hat viele Schwierigkeiten, und nimmt die Geduld des Arztes häufig in hohem Grade in Anspruch. Die unstäten, zuckenden Bewegungen der Augenmuskeln, welche nic dem Willenseinflusse gehorchen, zeigen sich bei allen Blindgebornen mit den Jahren so zunehmend, dass sie öfters einen hohen Grad von Strabismus alternans bedingen, und ohne künstliche Fixirung des Auges die Ausführung der Operation fast unmöglich machen. Dazu kommt dic so häufig beobachtete Zähigkeit der Linsenkapsel, welche das Finschneiden bei der versuchten Zerstückelung erschwert und die Neigung zum Wiederverkleben der nur wenig klaffenden Einschnitte begünstigt. Hat man nicht gerade einen Milchstaar vor sich, dessen Inhalt nach dem Einstiche der ungetrübten Kapsel sogleich ausfliesst, so ist auf eine schnelle Aufsaugung des Staars nach der Zerstückelung so wenig zu rechnen, dass die Operation in der Regel wiederholt werden muss. Abcr auch in diesem Tialle bleiben fast immer getrübte Kapselreste zurück, wolche bei der gewöhnlich durch Keratonyxis verrichteten Operation auch bei stark erweiteter Pupille nur höchst schwierig vollkommen dislocirt werden können. Als günstigen Umstand muss man dageyen dic geringe Neigung $z u$ entzündlicher Reaction betrachten. Der operative Eingriff bleibt in der Regel ohne alle nachtheilige Folge, so dass man dreist beide Augen zugleich operiren, und die Operation nach kurzen Zwischenräumen wiederholen kann.

Dic crwihnten Uebelstände, welche ich bei den orsten durch Keratonyxis ausgeführten Zerstückelungen ohne Ausnahme beobachtete (die nach Saunders zweimal versuchte Finschneidung des Centrums der vorderen Kapsel mit seichten Schnitten in die Linsensubstanz blieb 
ganz ohne Erfolg), veranlassten mich, in späteren Fällen die Scleroticonyxis zu wählen, welche entschieden bessere Resultate geliefert hat, ohne je eine merklich nachtheilige Reaction zu bedingen. Ein einziges Mal sah ich einige Stunden nach der Operation eines halbjährigen Kindes Erbrechen eintreten, welches bei der stattgefundenen Zerstückclung völlig gleichgültig blieb. Dic Reclination ist mir niemals bei ganz kleinen Kindern gclungen. Bei cinem zehnjährigen Knaben glückte sic an einem Augc, doch hob sich der Staar nach einigen Tagen wieder wegen unruhigen Verhaltens, so dass nachträglich die Zerstückelung vorgenommen werden musste. Bei kleinen Kindern bediene ich mich einer Langenbeck'schen Keratonyxisnadel, welche leicht durch die Sclerotica cingeführt werden kann, suche stets die vordere Kapsel zunachst mit verschiedenen, sich im Centrum durchkreuzenden Schnitten zu trennen, und grössere Stückchen der hierauf zerschnittenen Linse in die vordere Augenkammer zu schieben. War ich auch bis jetzt noch nie so glücklich, mit der ersten Operation ein ganz befricdigendes Resultat zu erlangen, so genügto doch in verschiedenen Fällen die zweite, um dic Pupille ganz rein zu machen. Jedenfalls sind die Vorzüge der Scleroticonyxis auch bei ganz kleinen Kindern so bedeutend, dass dieselbe allgemeiner ausgeübt $\mathrm{zu}$ werden verdient. Grössere Schwierigkeiten nls die Keratonyxis bietet sic kaum dar. Wartet man den gehörigen Moment zum Einstiche $a b$, so lässt sie sich in der Regel ohne künstliche Fixirung des Augapfels ausführen. Bei grosser Unruhe des Auges habe ich die Fixirung desselben mit einer in die Bindehaut eingesetzten, von einem Gehülfen gehaltenen Zahnpincette leicht bewerkstelligt.

Minder leicht ist die Fixirung der kleinen Kinder selbst, un die Operation mit gehöriger Sicherheit verrichten zu kümnen. Ich lasse dieselben, mit an den Leib 
gelegten Armen fest eingewickelt, von einem zuverlässigen Gehülfen in halb sitzender Stellung auf dem Schoosse halten, während cin zwciter dahinter stehender Gehülfe den Kopf nebst dem oberen Augenlide fixirt, und operire vor dem kleinen Patienten sitzend, dessen eingewickelte Beine mit den Obcrschenkeln umschlicssend. Auf diesc Weise ist es mir jedesmal gelungen, die Operation ungehindert auszuführen.

Da die Blindheit auf die ganze Entwickelung des Kindes einen so nachtheiligen Einfluss ausübt, so nehme nan die Operation möglichst frühzeitig, am besten vor Eintritt der Dentition, vor. Die Gefahr der Operation wird durch das zarte Alter nicht im mindesten vergrüssert, die frühzeitige Operation hat aber den nicht hoch genug anzuschlagenden Vortheil, dass sie der mit dem Alter stets zunehmenden Instabilität der Augäpfel, welche sich bei spät Operirten nicht immer verliert, am sichersten Schranken setzt.

Die Nachbehandlung beschränkt sich bei ganz kleinen Kindern hauptsächlich auf Verfinsterung des Zimmers und Bedeckung der Augen mit einer leichten Compresse, welche übrigens oft die Unruhe vermehrt und abgerissen wird. Bei Säuglingen kann von einer Veränderung der Diät nicht die Rede sein. Entwöhnten Kindern gebe man mehr flüssige Nahrung, und achte darauf, den etwa fehlenden Stuhlgang durch Klystire zu befördern.

Meine Erwartung, dass bei frühzeitig operirten Kindern das Accommodationsvermügen sich so stark ausbilden werde, um den Verlust der Linse auszugleichen, hat sich nicht bestätigt. Erst im vorflossenen Winter wurde mir ein neunjähriges, im ersten Lebensjahre von mir an bciden Augen operirtes Mädchen von der Lehrerin zugeschickt, weil dasselbe, angeblich wegen Kurzsichtigkeit, dem Unterrichte nicht gehörig zu folgen im 
Stande sei. Als ich demselben ein Convexglas vorhielt, sah es augenblicklich deutlich, so dass ich zu einer Staarbrille rathen musste. Gleiches habe ich früher schon bei anderen Operirten wahrgenommen.

Im Ganzen habe ich acht Blindgeborne in einem Alter von 6 Monaten bis 12 Jahren operirt, und zwar sämmtliche an beiden Augen. In zwei Fällen war der Erfolg ganz ungenügend. Bei einem mit Cataracta pyramidata behafteten einjährigen Kinde erfolgte auf dic einmalige Zerstückelung durch Keratonyxis keine Resorption. Eine Wiederholung der Operation konnte ich nicht vornchmen, da sich die auswärts wohnenden Aeltorn nie wieder mit dem Kinde bei mir einfanden. In dom zweiten Falle, wo ich nach Saunders mich auf die blosse Einschneidung der Kapsel beschränkt hatte, welche ohne Schwierigkeit ausgeführt wurde, traten am dritten Tage nach der Operation Convulsionen mit tödtlichem Ausgange ein. Im Auge war nicht die mindeste Reizung wahrzunehmen, so dass die Operation um so weniger als Veranlassung des so tragischen Erfolgs angesehen werden konnte, als, wie ich später erfuhr, schon einige Geschwister des halbjährigen Kindes einer gleichen Krankheit erlegen waren. Bci den übrigen 6 Opcrirten hatte ich Ursache, mit dem Resultate zufrieden zu sein. Fünf derselben wurden vollständig hergestellt, sämmtlich durch Scleroticonyxis operirt, während der sechste, ein in zehnten Lebensjahre durch Keratonyxis operirter Zügling der hiesigen Blindenanstalt, an einem Auge eino fast reine Pupille bekam, jedoch wegen zuckender Bewcgungen der Augäpfel keinen ganz freien Gebrauch des Gesichts davon trug, so dass cr, aus der Anstalt entlassen, später wieder aufgenommen wurde, wo er den Blinden als Führer diente. An dem anderen Auge extrahirte ich später die zurückgebliebene getrübtc Kapsel. Das Gesicht besserte sich jedoch kaum, wiewohl die 
Pupille frei geworden war, so dass der nicht ganz befriedigende Erfolg bei diesem Patienten wohl einer angebornen Amblyopie zugeschrieben werden muss. In cinem der glücllich operirten Fälle, bei einem in der lintwickelung zurückgeblicbenen, scrophulösen, $\frac{5}{4} \mathrm{j}$ ǰhrigen Müdchen, welches früher an wiederholten Anfällen von Meningitis tuberculosa gelitten hatte, konnte man sich crst so spät von dem Eintritte der Sehfunltion überzeugen, dass die Vermuthung einer amaurotischen Erblindung gerechtfertigt schien. Allmählig hat sich aber der Gesichtssinn in befriedigendern Grade entwickelt*).

VII. Amarose durch Farben der Kopfhare mit einem bleihaltigen Mittel.

Vor drei Jahren wurde ich zu einer 57jährigen, etwas schmächtig ausschenden, aber durchaus nicht entkräfteten Frau wegen vollkommener, rasch entstandener Erblindung beider Augen gerufen. Von einer seit vielen Jahren bestandenen Geschwulst im Unterleibe ausgehende, verhältnissmässig geringe Beschwerden abgcrechnet, befand sich die Frau angeblich wohl, bis sie nach mehrtägigem Kopfwch vor drei Tagen am rechten Auge plötzlich erblindete. Von ihrem Hausarzte behandelt,

*) Als Curiosum mögc folgente Staaroperation hicr cine Stelle finden. Bei Gelegenheit cines Krankenbesuchs zeigte mir die Fran eines Landgeistlichen cin junges IIulın, welches wegen Blindheit aus der Irnnd gefüttert werden musstc. Ich fand an beiden Augen milchweisse Cutaracten, verfertigte mir aus einer feinen englischen Nälınadel, die ich in eine abgeschnittene Fcder cinklemmte, eine Staarnadcl, womit ich dic Xierntonyxis dureh dic äusscrst kleine Pupille vollzog. Bei dem Einstiche in die Kalpscl floss ein Tröpffhen weisslicher Flüssigkeit hervor. Zur Nachbehandlung rieth ich, das Hühnchen einige Tage an einem dunkeln Orte cinzusperren. Als jch nach einigen Wochen wiederkehrte, wurde mir dasselbe als schend gezeigt. Beide Pupillen waren rein schwarz geworden, und das Thierehen konnte sein Futtcr finderi. 
erwachte sie am vierten Morgen auch am anderen Auge völlig blind. Ich fand beide Pupillen in solchem Grade crweitert, dass nur cin schmaler Ring der Iris zu entdecken war, vollkommen unbeweglich, etwas rauchig, die Bindehaut der Sclerotica mit stark erweiterten Gefässstämmen durchzogen, in dcren Zwischenräumen sich ein Netz feiner Gefässchen ganz unregelmässig bis in die Nähe der Hornhaut verzweigte. Dic Augäpfel waren stark gespannt, empfindlich bei der Berührung, starr, da jede Bewegung derselben cine hüchst lästige Spannung verursachte. Der heftige,-über die ganze Stirn ausgebreitete Kopfschmerz dauerte fort, die Stirn fühlte sich heiss an, und der Puls zeigte bei sehr bedentender Frequenz cine höchst auffallende Härte. Die Blindheit war eine so complette, dass auch der stärkste Lichtreiz gar keinen Eindruck machte. Der mässig gespannte Unterleib schmerzte bei der Berühung, was Patientin von einer bei ihr nicht ungewöhnlichen, mehrtägigen Verstopfung ableitete. Ohne den mindesten Aufschluss über das Ursächliche dieser so ungewöhnlich rasch entstandenen Amaurose erhalten zu können, stützte ich meinen Heilplan auf die objectiven Frscheinungen, und verordnete, eine an Entzündung grenzende acute Hyperämic der Chorioidea diagnoscirend, cine starke Venäsection an Arme, innerlich Calomel in Purgirdosen, Einreibungen von Mercurialsalbe in die Supraorbitalgegend, ein eröffnendes Klystir nebst reizenden Fussbädern. Wiewohl das Calomel mehrere reichliche Stuhlgänge bewirkt hatte, zeigten sich doch schon am dritten Tage die Vorboten des Speichelflusses, welche mich aber um so weniger bestimmten, den Heilplan zu ändern, als Paticntin ziemlich deutliche Lichtempfindung bekommen hatte. Erst am fünften Tage wurde das in kleineren Gaben fortgebrauchte Calomel wegen des ausgebrochenen Spcichelflusses durch ein Pulver aus Bittersalz mit Schwefel 
ersetzt. Am achten Tage erkannte Patientin bei gemässigtem Speichelfusse dic Umrisse aller Objecte im Zimmer ziemlich deutlich, aber farblos, wie in Rauch gehüllt. Die Pupillen hatten sich merklich verengert, reagirten etwas auf das Licht, der Schmerz in der Stirn war verschwunden.

In dieser Periode erhielt ich durch eine Hausgenossin der Patientin einen überraschenden Aufschluss über die Entstehung der Blindheit. Patientin hatte nämlich ihre ganz ergraueten Kopfhaare schon seit geraumcr Zeit, zuletzt kurz yor dem Erblinden, mit einem Geheimmittel gefärbt, wovon man mir noch einen ziemlichen Vorrath in einem Topfe zeigte. Die schwarze, consistenter Stiefelwichse ähnliche, breiige Masse war mir von früherher schon bekannt als eine Verbindung von Bleiglätte mit Kalk, welche in ein Tuch geschlagen während der Nacht auf den Kopf gebunden wird, um den Haaren eine dunkle Farbe zu geben. Dass bei dieser Anwendungsweise alle Bedingungen zur Begünstigung der Resorption dieses schädlichen Mittels vereint sind, ist einleuchtend. Von der nachtheiligen Wirkung auf die Augen hatte ich mich aber schon durch zwei früher beobachtete Fälle überzeugt. Da die Erblindung in dem gegenwärtigen Falle nicht als Symptom der Bleikolik auftrat, das eingeschlagene Verfahren unbewusst der Causalindication entsprochen hatte, so konnte ich kaum eine wesentliche Aenderung eintreten lassen. Zur Beseitigung der muthmasslich noch bestehenden Stockungen in der Chorioidea schritt ich jetzt um so entschiedener zur Anwendung grosser Dosen von Jodkali, als ich dadurch die letzten Spuren des Speichelflusses zu tilgen hoffte. Dass dieses Mittel überdies am geeignetsten ist, das Blei durch die Nieren zur Ausscheidung zu bringen, würde ich als Hauptmotiv vorangestellt haben, wenn mir die Erfahrungen von Parkes damals schon bekannt 
gewesen wären. Das Mittcl entsprach übrigens meinen Erwartungen insofern, als Patientin vierzehn Tage nach dem Eintritte der Blindheit so weit hergestellt war, dass sie selbst kleine Gegenstände in scharfen Umrissen und in natürlicher Färbung unterscheiden konnte. Zu lesen vermochte sie jedoch nicht. Eine stärkende Nachkur hatte für die Augen keine weitere Besserung zur Folge, und eine Brille nützte so wenig, das Patientin diesclbe wieder ablegte. Sieben Monate nach dem Beginn der Blindheit gebrauchte sie die Thermen von Baden im Canton Aargau, kehrte ohne Besserung des Gesichts zurück, und starb ein Jahr später, dem Vernehmen nach an den Folgen der oben erwähnten Unterleibsgeschwulst.

Der hier geschilderte Fall entspricht hinsichtlich der Symptome und des Verlaufs, namentlich der überraschend schnellen Ausbildung, genau der von Beer, Duplay u. A. beschriebenen $\Lambda$ maurosis saturnina, ohne jedoch von den Erscheinungen der Bleikolik begleitet gewesen zu sein. Eine Entstehung der Krankheit aus der erwähnten Ursache war mir früher unbekannt, bevor ich bei zwoi anderen Patienten, bei Männern, die gleiche Beobachtung gemacht hatte. Bei beiden trat die Amaurose unter ganz torpider Form auf, begann nicht so stürmisch, widerstand aber leider allen IIeilversuchen. Beer bezeichnet den Missbrauch bleihaltiger Schminke als veranlassendes Moment, ohne sich aber auf einen bestimmten Fall zu beziehen.

VIII. Merkwürdige Folgen von Augenverletzung durch den Stoss mit dem Horne einer Kuh.

Gar nicht selten habo ich bei Landleuten Verlust des Auges aus der erwähnten Ursache beobachtet, ohne diese Fälle, welche an sich nichts Besonderes darbieten, 
hier berühren zu wollen. Eine merkwürdige Folge sah ich vor einem Jahre bei einem älteren Manne, welchem eine Kuh das Auge etwas unsanft mit der Spitze ihres Horns berührt hatte. Lis war schon längere Zeit seit diesem Unfalle verflossen, als sich der Mann an mich wandte, weil er fortwährend von einer unangenehmen Empfindung bei der Bewegung der Augenlider belästigt wurde. Bei dem ersten Blicke entdeckte ich an dem oberen Seitentheile des Augapfels, ganz in der Nähe der Hornhaut, eine runde, scharf begrenzte, flache Erhebung der Bindehaut der Sclerotica, durch einen unter ihr liegenden, etwas beweglichen, festen Körper veranlasst. Form und Grösse entsprachen genau der einer Krystalllinse, so dass ich nicht im Zweifel sein konnte, einen durch Ruptur der Sclerotica erfolgten Austritt der Linse unter die Bindehaut, eine Mernia lentis crystallinae, vor mir zu haben. Einen wahrscheinlich durch die Linse verdeckten Einriss der Sclerotica konnte ich nicht ermitteln. Die Hornhaut war unversehrt, die Pupille starr, in hohem Grade erweitert. $\mathrm{Da}$ das Gesicht an diesem Auge schon seit vielen Jahren erloschen war, so verstand sich Patient leider nicht dazu, die Fixtraction vornehmen zu lassen. Ich sah denselben nur einmal nach einigen Monaten in ganz unverändertem Zustande wieder.

An einen weit merkwürdigeren Fall der Art erinnerte mich vor einiger Zeit Herr Dr. Bourgeois, welcher denselben vor vielen Jahren in der Poliklinik mit beobachtet hatte. Ein junger Mensch, welcher von einer Kuh in ein seit längerer Zeit erblindetes Auge gestossen wurde, erlangte bald darauf sein Gesicht wieder. Bei der später vorgenommenen Untersuchung des Auges zeigte sich dasselbe ganz normal, ohne alle Spuren einer stattgefundenen Verletzung. Das Gesicht war übrigens 
minder scharf, als an dem anderen $\Lambda$ uge. Als eine Loupe zur Untersuchung benutzt wurde, sah der junge Mensch augenblicklich so gut, dass er durch das vorgehaltene Glas zu lesen im Stande war. Unterlag es hiernach keinem Zweifel, dass die Linse fehlte, so durfte mit Sicherheit geschlossen werden, dass Patient von einer vorausgegangenen Cataracta durch Resorption in Folge der wahrscheinlich mit Ablüsung oder Ruptur der Kapsel verbundenen Erschütterung des Auges befreit worden war. Es hatte somit eine geviss seltene Staaroperation durch eine Kuh stattgefunden.

\section{Kochsalz als Augenmittel.}

Schon längst als Augenmittel bekannt, in v. Gräfe's Repertorium augenärztlicher Heilformeln aufgenommen, wurde das Kochsalz von Tavignot in sehr starker Solution (15-30 Grammen auf 125 Grammen Wasser) als Collyrium, vorzüglich bei scrophulösen Ophthalmieen mit Geschwürbildung, so dringend empfohlen, dass ich mich zu Versuchen mit demselben entschloss. Seit mehreren Jahren habe ich dasselbe so häufig in der Poliklinik und Privatpraxis angewendet, dass ich mir ein Urtheil darüber zutrauen darf. Als Bestandtheil der Thränen ist das Kochsalz dem Auge weit homogener als viele andere, scheinbar indifferentere Mittel, und verursacht eine verhältnissmässig geringe Irritation, welche überdies nie von langer Dauer ist. Daher ist es begreiflich, wie Tittmann schon vor langer Zeit eine ganz gesättigte Kochsalzlösung gegen Hornhautflecken, Tavignot das Mittel in Substanz gegen Kornhautgeschwüre anwenden konnten. In seiner Wirkung auf die Bindehaut und Hornhaut dem Höllenstein am nächsten stehend, wenn dieser nicht als Causticum benutzt wird, 
leistet das Mittel bei Auflockerung der Conjunctiva mit starkem Gefässwucher Bcdeutendes, besonders aber bei oberflächlichen Injectionen der IIornhaut scrophulüser und impetiginöser Subjecte, mögen sie mit oder ohne Geschwürbildung auftreten. Ohne die Injection der Umgebungen der Geschwüre zu vermehren, reinigt es den Geschwürsgrund, und befürdert den Vernarbungsprocess ganz in derselben Weise, wie Höllenstein. Dass es schneller als dieser wirke, künnte ich nicht behaupten. Fintschieden ist die Wirkung des Hüllensteins eine günstigere bei tiefer greifenden entzundlichen Leiden der Hornhaut, mit noch nicht organisirtem Exsudat in deren Substanz, während es diesen bei oberflächlichen, nicht blennorrhoischen Affectionen der Bindehaut und Hornhaut der erwähnten $\Lambda$ rt vollkommen zu ersetzen vermag. Bei catarrhalischen Bindehautentzündungen unter mehr torpider Form ist das Kochsalz gleichfalls mit Nutzen anzuwenden, ohne jedoch einen Vorzug vor dem essigsauren oder schwefelsauren Zink und ähnlichen Metallsalzen zu besitzen. Gehört dasselbe unbestreitbar zu den wirksameren Localmitteln, so ist doch dessen Kinführung in die Augenheilkunde nicht als wesentlicher Gewinn zu betrachten, da es den Höllenstein nur in gewissen Fällen, dieser aber jenes überall ersetzen kann. Niemals habe ich mich so starker Solutionen wie $\mathrm{Ta}$ vign ot bedient, gewöhnlich 2-4 Gran auf eine Unze destillirten Wassers, bisweilen mit Opiumtinctur versetzt. Die Eigenschaft, in Substanz mit der Bindehaut in Berührung gebracht Entzündung derselben zu erregen (J. Hoppe, medicinische Briefe. Elftes Heft. Freiburg i. B. 1854. S. 333), theilt das Kochsalz mit vielen anderen gegen torpide Ophthalmieen benutzten Localmitteln. 
X. Beobachtung eines Falles von Scintillatio oculi.

Seitdem Parfait-Landrau einen merkwürdigen Fall von beweglichen, flimmernden Körperchen innerhalb des Augapfels mitgetheilt hat, ist dieser früher fast ganz unbeachtet gebliebenen Erscheinung eine grössere Aufmerksamkeit gowidmet worden, während eine ältere, hierher gehörige Beobachtung von Joh. Adam Schmidt (v. Ammon's Zeitschr. f. d. Ophthalmologie. Bd. I. S. 382) erst durch Stellwag (die Ophthalmologie vom wissenschaftlichen Standpunkte aus bearbeitet. Freiburg 1853. Bd. I. S. 717) in Erinnerung gebracht wurde. Schmidt erwähnt nämlich, dass sich die vordere Fläche einer gypsartigen Cataracta in Form eines feinen, glänzend rothen, silbernen und goldenen Pulvers abstäubte, und einen liniendicken Satz von diesem farbigen Staube in dem Boden der vorderen Augenkammer absetzte. Machte das Bauermädchen (25 Jahre alt) Beugungen mit dem Kopfe, oder rieb man das Auge mittelst des oberen Augenlides, so vertheilte sich der glänzende Satz durch die wässerige Feuchtigkeit der vorderen Augenkammer, und setzte sich nach einigen Minuten wieder. Als Barth den Hornhautschnitt machte, floss dieser Glanzstaub mit der wässerigen Feuchtigkeit heraus, den man auf einem weissen Kartenblatte aufsammelte. Mit der wässerigen Feuchtigkeit floss auch der aufgelöste Glaskörper aus, und das Auge fiel zusammen. Das Auge fühlte sich ausserordentlich weich an, nach Schmidt's Ausdruck wie eine überzeitige Feige. In neuerer Zeit ist eine ziemliche Zahl ähnlicher Beobachtungen zur Veröffentlichung gelangt, welche Schauenburg (Ceber Cholestearinbildung im menschlichen Auge. Erlangen 1852) 
auf 23, Blasius (Deutsche Klinik. 1852. N. 17. S. 185) auf '2.4 bestimmt. Diese Angaben sind aber nicht vollständig. Als Nachtrag zu Schauenburg sind noch beizufügen die Fälle von

1) Joh. Adam Schmidt a. a. O.

2) Kanka, Med. Jahrb. d. k. k. österr. Staates. 1847. Oct. S. 66.

3) Paul IIervier, récherches sur le synchysis étincclant, d'après l'obscrvation d'une nouvelle variété recueillée à la clinique de M. Petrequin. Gaz. méd. de Paris. 1848. N. 46 , pag. $884 \mathrm{ff}$.

4) Günsburg, Deutsche Klinik. 1850. N.8. S.78.

5) O.Fischer, Deutsche Klinik. 1850. N.17. S.188.

6) Demarres, Gaz. méd. de Paris. 1830. N. 37. pag, 670. D. erwähnt hier einige neue Fälle.

7) Einem Ungenannten in der med. Zeitung Russlands. 1851. N. 3 .

8) Tél. Desmartis, Rév. thér. du Midi. Mar's 1853.

Nimmt man die von Desmarres erwähnten neueren Fälle nur zu 2 an, da er keine Zahl angibt, so wären bis jetzt mit dem von mir beobachteten 33 bekannt. Dic Zählung kann übrigens, ungeachtet der geringen Menge, leicht ein abweichendes Resultat liefern, da verschiedene Fälle von mehreren Beobachtern beschrieben worden sind, Manche wiederum mehrere Fälle beobachtet haben. Seitdem S to u t (Gaz. méd. de Paris. 1847. N.4. 23 Janv.) in dem lebenden Auge die durchsichtige, krystallinische Beschaffenheit der flimmernden Körperchen durch mikroskopische Untersuchung erkannt, und Becker (Norsk Magaz. for Lägevïdenskaben. 1849. 3. p.782. S chmid t's Jahrbb. 1851. N. 1. S. 104) in dem abgelassenen Humor aqueus dieselben mit Bestimmtheit als Cholestearinkrystalle nachgewiesen hat, kann übei die Natur derselben 
kein Zweifel mehr obwalten. Man hat sich über diesen Punkt so allgemein verständigt, dass man öfters so weit gegangen ist, die Nachweisung dieser Krystalle bei der Zergliederung todter Augen als genügenden Bewcis für die Annahme einer Scintillatio oculi zu betrachten. Alle dicse Falle aber, in welchen die Erscheinung dos Flimmerns im Leben nicht wahrgenommen wurde, sind nicht unter die oben erwähnten aufgenommen. Eine grössere Meinungsverschicdenheit herrscht über den Sitz der flimmernden Körperchen, welche Desmarres in den Glaskörper verlegte, und darum die am häufigsten gebrauchte Benennung Synchysis scintillans vorschlug. Da aber das Flimmern ganz entschieden auch in anderen Theilen des Auges nachgewiesen wurde, sehr häufig von der Linse, besonders nach Staaroperationen oder freiwilligem Verschwinden eines Staares durch Senkung oder Resorption ausgeht, ohne immer von den Erscheinungen einer Auflösung des Glaskörpərs begleitet zu sein, so ist die Bezeichnung Synchysis scintillans als eine generelle $\mathrm{zu}$ verwerfen. Einleuchtend ist es übrigens, dass im Glaskörper befindliche Cholestearinkrystalle nur dann als bewegliche erscheinen können, wenn dicser wenigstens theilweise verflüssigt ist, wie dies nach den meisten Nadeloperationen vorkommt. Dass die Cholestearinkrystalle Produkte vorausgegangener Chorioideitis seien, und sich dann bilden, wenn das Exsudat verknöchert ist, oder sich zu verknöchern beginnt, wie A. G. (Med. Zeitung. Herausgegeben von dem Verein für Heilkunde in Preussen. 1849. N. 5. S. 247) behauptet, lässt sich nicht in Abrede stellen, ohne aber deshalb eine andere Bildungsweise auszuschliessen. Nach dem gegenwärtigen Stande der Untersuchungen muss mit Gewissheit angenommen werden, dass die entzündlichen Exsudate verschiedener Particen des Au- 
ges unter freilich noch zu ermittelnden Bedingungen fühig sind, Cholestearinkrystalle abzusetzen, die O. Fischer sogar in ciner zwischen den Hornhautlamellen befindlichen Hühle als bewegliche Flimmern wahrgenommen hat.

Der von mir beobachtete Fall ist folgender:

Eine 70jährige, schwächliche, seit vielen Jahren mit Gliederschmerzen behaftete Frau vom Lande, seit frühel Kindheit am rechten Auge durch ein Hornhautstaphylom erblindet, verspürte in Folge wiederholter Entzündungsanfälle eine allmählige Abnahme der Sehkraft am linken Auge, welche seit einem Jahre in complette Blindheit übergegangen ist. Der behandelnde Arzt diagnoscirte Cataracta, erklärte diese schon vor einem Jahre für reif, und rieth zur Operation, zu welcher sich die Frau lange nicht verstehen wollte. Bereits im Voraus von der Absicht der Patientin, sich von mir operiren $z u$ lassen, unterrichtet, war ich im höchsten Grade erstaunt, statt der vermutheten Cataracta ein ganz anderes Uebel zu finden. Die mässig erweiterte, etwas in die Quere verzogene, unbewegliche Pupille zeigte tief im Hintergrunde einen schwachen graugrünlichen Schimmer, wie bei geringerem Grade des Glaukoms. In der Bindehaut der Sclerotica befanden sich einzelne stark erweiterte Gefässe. Die graublaue, etwas matt aussehende Iris machte schwankende Bewegungen. Der Augapfel war in sciner Consistenz unverändert, das Sehvermögen so vollständig erloschen, dass selbst das grelle Sonnenlicht keinen Eindruck machte. Unter diesen Umständen Amaurose als Folge von Chorioideitis mit Exsudation unter die Retina diagnosticirend, war es mir ganz unbegreiflich, wic ein solcher Fall mit Cataracta verwechselt werden konntc. Ich dachte deshalb an die Müglichkeit einer 
freiwilligen Senkung oder Aufsangung eines früher vorhanden gewesenen Staars, wofür die Iridodonesis einigermaassen zu sprechen schien, und erweiterte die $\mathrm{Pu}$ pille künstlich, namentlich in der Absicht, cinen Versuch mit den Purkinje'schen Lichtbildern anzustellen. Bei der Betrachtung des Auges im Zustande der Pupillenerweiterung bot sich meinem Blicke ein höchst überraschendes, bis jetzt noch nie gehabtes Schauspiel dar. Der ganze Hintergrund des Auges war nämlich mit zahllosen, goldsandähnlichen Körperchen wie übersäet, welche in fortwährender Bewegung durcheinander wirbelten, sich abwechselnd hoben und senkten, durch die Bewegungen des Auges emporgeschnellt, vermöge ihrer Schwere unter kleinen Oscillationen herabfielen, um, kaum am Boden angelangt, in der gleichen Weise zum Vorschein zu kommen. Wic von einer Quelle emporgewirbelter Sand (einen besseren Vergleich wüsste ich nicht zu finden) stiegen sie bis gegen die Mitte der stark erweiterten Pupille, offenbar aber in ziemlicher Entfernung von dieser auf, da sie bei seitlicher Betrachtung des Auges nicht sichtbar waren, und senkten sich mit solcher Schnelligkeit nieder, dass der Blick den cinzelnen Flimmern um so schwerer folgen konnte, als diese häufig von anderen verdrängt oder verdeckt wurden, bevor sie ihre kurze Bahn durchlaufen hatten. Die ganze Bewegung wiederholte sich mit solcher Regelmässigkeit, dass man einzelne grössere Körperchen von ausgezeichneter Gestalt, nach kurzen Pausen, mit Bestimmtheit wieder auftauchen sah. Diese waren unregelmässig zackig, länglich, während die Gestalt der kleineren unmöglich $\mathrm{zu}$ bestimmen war. Durch die Loupe betrachtet, erschienen sie sämmtlich weit weniger glänzend. Bei ruhiger Haltung des Auges hörte die Bewegung wie abgeschnitten auf, sämmtliche Körperchen 
verschwanden auf dem Augengrunde, von wo sic durch das geringste Zucken des Augapfels sogleich wieder auftauchten. Als die Pupille auf ihren normalen Durchmesser zurückgekehrt war, zeigte sich das scheinbare Leben im Hintergrunde des Auges erloschen, so dass keine Spur einer Bewegung an den Stellen, wo sie früher so deutlich $z u$ erkennen war, dass sie ausser von einigen Studirenden auch von den Angehörigen der Patientin sogleich wahrgenommen wurde, entdeckt werden konnte.

Vor Kurzem hatte ich Gelegenheit, die Frau wieder zu untersuchen. In Folge einer Iritis hat sich die Pupille in solchem Grade verengert, dass sie kaum stecknadelknopfgross ist. Wiewohl das Centrum frei von Exsudat ist, welches an der ganzen kleinen Zone das Gewebe alienirt hat, so gelang es doch leider nicht, eine Krweiterung der Pupille durch Finträufelung ciner Atropinlösung za Stande zu bringen.

Nachträglich sei noch erwähnt, dass bei der Untersuchung des Auges mit einer vorgchaltenen Kerze nur ein aufrechtstehendes Lichtbild erschien, so dass wohl ohne Zwcifel hier cine Cataracta durch Resorption geschwunden war, da im Augengrunde keine Spur einer solchen bei stark erweiterter Pupille entdeckt werden konnte. Merkwürdiger Weise war das Flimmern bei dem Kerzenlichte nicht deutlich sichtbar, woran übrigens der Umstand einigen Antheil haben mochte, dass das Zimmer, in welchem ich die Untcrsuchung wegen beeilter Abreise der Patientin bei Tage vornahm, nicht ganz verfinstert werden konnte. Der Fall scheint unbezweifelt sich denjenigen anzureihen, bei welchen der Sitz der flimmernden Kürperchen im Glaskürper zu suchen ist. Wahrscheinlich befanden sich dieselben in der Nähe des Augengrundes, weil sie nur dann zur Wahrnehmung gelangten, wenn bei Erweiterung der Pupille die 
Erleuchtung des inneren Auges stark genug war, um die zum Sichtbarwerden erforderlichen Lichtstrahlen zu bedingen, und das Flimmern, wie bereits erwähnt, bei seitlicher Betrachtung nicht wahrgenommen wcrden konnte. Dieser Umstand ist von den bisherigen Beobachtern unerwähnt geblieben, und kann auf die der Pupille näher befindlichen Flimmern begreiflicher Weisc keinen Einfluss äussern. Dass aber manche Fälle von Scintillatio oculi aus diesem Grunde der Walunehmung entgehen, unterliegt so wenig einem $Z$ weifel, als ich dio Beobachtung des erwähnten Falles nur einem glücklichen Zufalle zu verdanken habe. 